\title{
Curing kinetics and ionic interactions in layered double hydroxides-nitrile rubber Mg-Al-LDHs-XNBR composites
}

\author{
Magdalena Lipińska ${ }^{1}$ (D) $\cdot$ Magdalena Gaca $^{1} \cdot$ Marian Zaborski $^{1}$
}

Received: 22 September 2019 / Revised: 20 March 2020 / Accepted: 2 June 2020 /

Published online: 18 June 2020

(c) The Author(s) 2020

\begin{abstract}
The carboxylated butadiene-acrylonitrile XNBR composites containing layered double hydroxides ( $\mathrm{Mg}-\mathrm{Al}-\mathrm{LDHs}$ ) were prepared with the aim to investigate the effect of various $\mathrm{Mg}$ : $\mathrm{Al}$ ratio in the filler composition on the rheological behavior, kinetic of curing and viscoelastic properties of final material. Due to the presence of metal cations, LDHs can form ionic cross-links with carboxylic functional groups of XNBR nitrile rubber. The DSC analysis indicated lower ranges of curing temperatures as the Mg:Al ratio raised $\left(90-184{ }^{\circ} \mathrm{C}\right.$ for Pural MG63, $88-187{ }^{\circ} \mathrm{C}$ for Pural MG70). The apparent energy of activation $E_{\mathrm{a}}$ decreased with increasing $\mathrm{Mg}: \mathrm{Al}$ ratio reaching the value of $111.46 \mathrm{~kJ}^{\prime} \mathrm{mole}^{-1}$ for XNBR composite containing Pural MG70. The rheological analysis revealed the presence of specific polymer-nanofillers and fillers-fillers interactions. The XNBR-LDHs rubbers exhibited two transitions corresponding to the glass temperature of elastomer $T_{\mathrm{g}}$ (in range of -13.08 to $-13.60{ }^{\circ} \mathrm{C}$ ) and the ionic transition temperature $T_{\alpha^{\prime}}$ (in range of $32.95-37.90{ }^{\circ} \mathrm{C}$ ). The ionic transition temperature $T_{\alpha^{\prime}}$ was not observed for the nitrile rubber composite containing Pural MG5 with the lowest Mg:Al ratio. The formed ordered ionic phase significantly affected the viscoelastic behavior of XNBR composites at room and sub-zero temperatures leading to the increase in the storage modulus $G$. Therefore, among the various possible applications of LDHs, their use in rubber technology offers the potential for production of environmentally friendly rubber products cured without any additional curatives.
\end{abstract}

Electronic supplementary material The online version of this article (https://doi.org/10.1007/s0028 9-020-03249-6) contains supplementary material, which is available to authorized users.

Magdalena Lipińska

magdalena.lipinska@p.lodz.pl

1 Institute of Polymer and Dye Technology, Lodz University of Technology, Stefanowskiego 12/16, 90-924 Lodz, Poland 


\section{Introduction}

Rubber is one of the most useful classes of materials that is applied in a broad range of fields due to its unique mechanical properties. Practically, the sulfur vulcanization is necessary to obtain significant enhancement in properties, such as toughness, elasticity and strength of rubber material. The formation of irreversible chemical cross-links brings the difficulties in processing and recycling of this way cured rubber [1]. Nowadays, the development of the dynamic, reversible cross-linked elastomers becomes the crucial issue of the environmental protection. Cross-linking induced by non-covalent interactions in rubber materials attracts a great interest. These cross-links can reversibly break and re-form under external stimuli, thereby allowing the easily processing and recycling of cured rubber [2-5]. The ionic elastomers are polymers containing a small amount (up to $10-15 \mathrm{~mol} \%$ ) of ionic functional groups. The carboxylated nitrile butadiene rubber $(\mathrm{XNBR})$ is a typical ionic elastomer, because of the presence of the carboxylic $(-\mathrm{COOH})$ functional groups along the hydrocarbon chain $[6,7]$. The structure of XNBR allows the formation of either covalent or ionic bonds [7-9]. The carboxylic salts can be formed between carboxylic groups and metal oxides (e.g., $\mathrm{ZnO}, \mathrm{MgO}, \mathrm{CaO}$ ) leading to the ionomers with the thermoplastic nature and the enhanced mechanical properties [10-13]. Many authors [6,14] reported that ionomer salts can associate to form two principal types of ionic phase: multiplets, statistically dispersed in polymer matrix, which do not form any separate phase, and aggregated clusters containing a higher amount of ion pairs as well as nonionic hydrocarbon content. Therefore, the properties of elastomers cured in such way strongly depend on the type of formed ionic phase. Multiplets act a similar way as physical cross-links. While clusters exhibit some properties of a separate phase including a special relaxation behavior, and they act not only as physical cross-links but also as a reinforcing phase [15].

Layered double hydroxides (LDHs) tend to be a promising material in preparation of the polymer and elastomer nanocomposites [16-20]. Layered double hydroxides LDHs are layered crystalline materials, with a general formula of $\left[\mathrm{M}^{\mathrm{II}}{ }_{1-x} \mathrm{M}^{\mathrm{III}}{ }_{x}(\mathrm{OH})_{2}\right]^{x+}\left(\mathrm{A}^{n-}{ }_{x / n}{ } \mathrm{mH}_{2} \mathrm{O}\right)^{\mathrm{x}-}$, where $\mathrm{M}^{\mathrm{II}}$ is a divalent metal ion, such as $\mathrm{Mg}^{2+}, \mathrm{Ca}^{2+}, \mathrm{Zn}^{2+}$ and $\mathrm{M}^{\mathrm{III}}$ is trivalent metal ion, such as $\mathrm{Al}^{3+}, \mathrm{Cr}^{3+}, \mathrm{Fe}^{3+}, \mathrm{Co}^{3+}$, and $\mathrm{A}$ is an anion with valence number of ( $n$ and $x / n)$ [21-23]. The crystal structure of these materials depends on the nature of cations and $\mathrm{M}^{\mathrm{II}} / \mathrm{M}^{\mathrm{III}}$ molar ratios [24]. The structure of most of them corresponds to the natural mineral, magnesium aluminum hydroxycarbonate, hydrotalcite $\mathrm{Mg}_{6} \mathrm{Al}_{2}(\mathrm{OH})_{16} \mathrm{CO}_{3} \cdot 4 \mathrm{H}_{2} \mathrm{O}$ [25]. Their properties such as high specific surface area $100 \pm 300 \mathrm{~m}^{2} \mathrm{~g}^{-1}$ [21-24], the ability to generate after calcination mixed metal oxides and to reconstruct the original LDHs structure by contact with solution containing anions resulted in increasing development of LDHs industrial applications [24]. Due to the fact that LDHs possess basic hydroxyl groups on their surface [26], they have potential as a reinforcing fillers in elastomers containing functional carboxylic groups (carboxylic butadiene-acrylonitrile rubber XNBR). Pradhan et al. [26] reported that the secondary interactions between surface of the LDHs fillers and XNBR 
elastomer matrix were formed and this way improved the reinforcing effect. The LDHs can affect the strain-induced crystallization of XNBR, and this way significantly improve the mechanical properties of rubber [26, 27]. Storage modulus of LDH-XNBR increased with increasing filler concentration. On the other hand, loss factor $\tan \delta$ maximum values decreased with increasing filler loading confirming the strong interactions at the filler-rubber interface [26, 27]. The ability of LDHs to interact with XNBR was confirmed by FTIR analysis [28, 29], with increasing content of the filler the intensity of the band corresponding to $-\mathrm{COOH}$ group decreased remarkably. Another important aspect is that LDHs may provide metal ions for reaction with the $-\mathrm{COOH}$ group, thereby leading to the formation of ion pairs similar way as it takes place for zinc salts [5], $\mathrm{ZnO}$ [15] and $\mathrm{MgO}$ [9]. For the XNBR containing zinc-aluminum layered double hydroxide $\mathrm{Zn}-\mathrm{Al}$-LDH no extra high-temperature dynamic relaxation process exhibited, although the ionic reactions with $-\mathrm{COOH}$ groups occurred [6]. The rheological data obtained by Arrigo et al. [29] demonstrated that the relaxation motions of the maleated poly(styrene-(ethylene-co-butylene)-styrene) copolymer chains were inhibited due to ionic interactions occurred between the functionalities grafted on SEBS$g$-MA and magnesium-aluminum layered double hydroxide $\mathrm{Mg}-\mathrm{Al}$-LDH. These ionic interactions were responsible for the formation of an inorganic-organic gellike structure. Previously, it was reported [14, 28, 30] that the Mg-Al-LDHs can be used as an alternative to conventional curing systems. This way the production of mechanically strong and transparent elastomer composites without any supplementary additives is enabled. It is huge ecological and economical benefit for layered double hydroxides (LDHs) to serve multifunctional suitability in XNBR, such as cross-linking substance, UV screener, thermal, mechanical and barrier property enhancer $[14,28,30]$.

In the present work, the commercially available $\mathrm{Mg}-\mathrm{Al}-\mathrm{LDHs}$ generated after calcination mixed oxides of various $\mathrm{Mg}$ : Al ratio were applied as a curing substances for carboxylated acrylonitrile-butadiene XNBR elastomer. The influence of $\mathrm{Mg}-\mathrm{Al}$ LDHs specific surface areas, and the tendencies to form filler-filler interactions on the dynamic viscoelastic behavior of the uncured and cured XNBR elastomer was analyzed. It was shown that the type of incorporated $\mathrm{Mg}-\mathrm{Al}-\mathrm{LDHs}$ affected the kinetic of XNBR curing, the range of curing temperatures and the apparent activation energy $E_{\mathrm{a}}$ of the process. The effect of $\mathrm{Mg}-\mathrm{Al}-\mathrm{LDH}$ with various structure on the kinetic of curing, the viscoelastic behavior and the processability of uncured rubber was not previously analyzed. The investigations proved that the commercially available magnesium rich LDHs can be applied at once as a reinforcing filler enhancing the dynamic mechanical properties of rubber at room and sub-zero temperatures, as well as a curing agent of carboxylated XNBR elastomer. The study evaluated the effects of various $\mathrm{Mg}-\mathrm{Al}-\mathrm{LDH}$ s structures on the formation of ionic clusters and the special relaxation behavior. 


\section{Experimental}

\section{Materials and preparation of rubber mixtures}

Various hydrotalcites and LDHs able to generate after calcination mixed metal oxides with various $\mathrm{MgO}: \mathrm{Al}_{2} \mathrm{O}_{3}$ ratio were applied before calcination as fillers and curing substances of carboxylated butadiene-acrylonitrile rubber XNBR: Pural ${ }^{\circledR}$ MG5 (Al-rich material with 5:95 MgO: $\mathrm{Al}_{2} \mathrm{O}_{3}$ ratio after calcination); Pural ${ }^{\circledR}$ MG30 (Al-rich material with 30:70 MgO: $\mathrm{Al}_{2} \mathrm{O}_{3}$ ratio after calcination); Pural ${ }^{\circledR}$ MG63 HT (Mg-rich material, hydrotalcite like analogue with 63:37 MgO: $\mathrm{Al}_{2} \mathrm{O}_{3}$ ratio after calcination); $\mathrm{Pural}^{\circledR}{ }^{\circledR} \mathrm{MG} 70 \mathrm{HT}$ (Mg-rich material, hydrotalcite like analogue with 70:30 $\mathrm{MgO}: \mathrm{Al}_{2} \mathrm{O}_{3}$ ratio after calcination), thereafter designed as MG5, MG30, MG63, MG70, products of Sasol. These materials were used without any modification as curing substances in amount of $30 \mathrm{wt} \%$ for carboxylated acrylonitrile-butadiene rubber XNBR (Krynac X750, Mooney viscosity ML $(1+4) 100{ }^{\circ} \mathrm{C}$ MU -47 \pm 5 MU-ISO 289/ASTM D 1646, specific gravity 0.99 , total ash $\leq 1.0 \mathrm{wt} \%$ ISO 247/ASTM D5668) containing 27 $\pm 1.5 \mathrm{wt} \%$ of acrylonitrile (ISO 24,698-1) and $\leq 7 \%$ of carboxylic group - $\mathrm{COOH}$ (FTIR spectroscopy), product of Arlanxeo. The XNBR formulas are listed in Table A1 (Supplementary Material). The Mg-AlLDHs-XNBR composites were prepared using a melt compounding method. The rubber and filler were homogenized using Brabender Measuring Mixer N50. The rubber compounds were processed using equivalent of $1.5 \mathrm{~s}^{-1}$ shear rate at the temperature of $80^{\circ} \mathrm{C}$. After 5 min of rubber mastication filler was added and mixed for additional $15 \mathrm{~min}$. Rubber mixtures before vulcanization were stored at $5{ }^{\circ} \mathrm{C}$. XNBR mixtures were molded and cured using electrically heated hydraulic press under a pressure of $5 \mathrm{MPa}$ at $180{ }^{\circ} \mathrm{C}$ during $60 \mathrm{~min}$. Cured sheets were conditioned before testing ( $24 \mathrm{~h}$ maturation at room temperature).

\section{Oil absorption measurement}

The oil absorption parameters OAP were measured according to ASTM D2414 using Absorptometer $\mathrm{C}$ equipment connected with Brabender station. The process parameters were: sample weight $20 \mathrm{~g}$, titration rate $4.0 \mathrm{ml} \cdot \mathrm{min}^{-1}$. The oil used in this study was dibutyl phthalate (DBP).

\section{The analysis of viscoelastic properties and complex viscosity of uncured XNBR compounds}

Rubber Process Analyzer RPA 3000 MonTech with lower die of the chamber oscillated sinusoidally at a fixed angle and frequency was used to characterize viscoelastic properties of uncured rubber compounds at temperature $80^{\circ} \mathrm{C}$. Behavior of uncured XNBR was studied according to ASTM D6204 standard. The RPA rheometer allows to apply different shear rates by either varying the frequency or varying the strain. The complex dynamic viscosity $\eta^{*}$ was measured based on frequency sweep tests, in which the 
frequency and strain amplitude were programmed to give the equivalent of $0.5-125 \mathrm{~s}^{-1}$ shear rate. The storage shear modulus $G^{\prime}$, loss shear modulus $G^{\prime \prime}$ and loss factor tan $\delta$ were measured at $80{ }^{\circ} \mathrm{C}$ in angular frequency range of $0.5-100 \mathrm{rad}^{\prime} \mathrm{s}^{-1}$ under constant low oscillation strain $(0.1 \%$, linear viscoelastic region) and high oscillation strain (100\%). The consistency index $K$ and the exponent of the potential equation $n$ were calculated by applying the power law [Eq. (1)] to the experimentally obtained values of the complex viscosity $\eta^{*}$ and shear rates $\gamma$.

$$
\eta=K \gamma^{n-1}
$$

\section{Enthalpy of vulcanization}

A DSC1 analyzer (Mettler Toledo) was applied to determine the range of curing and the enthalpy of the process for XNBR compounds. Measurements were taken in temperature range of -80 to $250{ }^{\circ} \mathrm{C}$ with a heating rate of $10^{\circ} \mathrm{C} \mathrm{min}{ }^{-1}$. Nitrogen was used as the protective gas at the flow rate of $80 \mathrm{~mL} \mathrm{~min}^{-1}$. The DSC exothermic curves were used to evaluate the enthalpy of vulcanization $(\Delta H)$, which is directly proportional to the area under the DSC curve. The values of the enthalpy of vulcanization $(\Delta H)$ were calculated by area integration software STAR ${ }^{\mathrm{e}}$ (Mettler Toledo) based on the exothermic peaks of curing in the studied temperature range $\left(-80-200{ }^{\circ} \mathrm{C}\right)$. Enthalpy of the curing $(\Delta H)$ corresponds to the integral of the exothermic peaks of curing with respect to time. And it was calculated using Eq. (2) [31].

$$
\Delta H=\int_{1}^{2} \frac{\mathrm{d} H}{\mathrm{~d} t} \mathrm{~d} t .
$$

\section{Kinetic of curing}

The curing studies were done at $140,150,160,170$ and $180{ }^{\circ} \mathrm{C}$ according to ASTM D5289, using RPA 3000 MonTech rheometer. The values of elastic torque $S^{\prime}$ as a function of time were used to calculate the kinetic parameters. The increment of elastic torque $\Delta S^{\prime}$ defined as $\Delta S^{\prime}=S_{\max }^{\prime}-S_{\min }^{\prime}$, where $S_{\max }^{\prime}$-maximum elastic torque, $S_{\text {min }}^{\prime}$ - minimum elastic torque, was calculated based on the curing curves. The range of temperatures studied and vulcanization parameters were chosen based on our previous studies [14] and based on the DSC measurements indicating the range of curing temperatures for every type of $\mathrm{Mg}-\mathrm{Al}-\mathrm{LDHs}-\mathrm{XNBR}$ formulas. From rheometric RPA experimental data, the cure rate $\alpha$ at time $t$ was calculated using Eq. (3):

$$
\alpha(t)=\frac{S_{t}^{\prime}-S_{0}^{\prime}}{S_{\infty}^{\prime}-S_{0}^{\prime}} .
$$

Experimental data were fitted to the empirical model (4) proposed by Isayev and Deng [32] to calculate the kinetic parameters of MG-XNBR compounds. 


$$
\frac{\mathrm{d} \alpha}{\mathrm{d} t}=\frac{n}{K} t^{-1-n} \alpha^{2}
$$

By taking $\alpha$ with respect to time, Eq. (4) can be expressed:

$$
\alpha=\frac{K \cdot t^{n}}{1+K \cdot t^{n}} .
$$

The rate constant $K$ of process and n-order of reaction were calculated using the rearranged Isayev's equation (6):

$$
\ln \left(\frac{\alpha}{1-\alpha}\right)=n \operatorname{lnt}+\ln K
$$

The apparent activation energy of ionic clusters formation $E_{\mathrm{a}}(\mathrm{kJ} / \mathrm{mole})$ was calculated according to an Arrhenius equations (7-8):

$$
\begin{gathered}
K=k_{0} \exp \left(-\frac{E_{a}}{\mathrm{RT}}\right) \\
\ln K=\ln k_{0}-\frac{E_{a}}{\mathrm{RT}}
\end{gathered}
$$

where $k_{0}$ is the pre-exponential factor, $\mathrm{R}$ is universal gas constant $(8.31447$ $\mathrm{J} \cdot \mathrm{mole}^{-1} \cdot \mathrm{K}^{-1}$ ) and $T$ is absolute temperature $(K)$.

\section{Glass transition $T_{g^{\prime}}$ ionic transition $T_{a^{\prime}}$ analysis and the characterization of rheological properties for cured rubbers}

The studies were carried out using Ares G2 oscillation rheometer under shear. The Ares G2 rheometer was equipped with parallel-plate geometry (diameter of $25 \mathrm{~mm}$ ). Firstly, to determine the glass transition $T_{\mathrm{g}}$ and ionic transition $T_{\alpha^{\prime}}$ temperatures, the measurements of mechanical loss $\tan \delta$ using the temperature sweep mode with a heating rate of $2{ }^{\circ} \mathrm{C} \min ^{-1}$ at constant angular frequency of $5 \mathrm{~Hz}$ and oscillation amplitude of $0.1 \%$ were conducted in a temperature range from -20 to $60{ }^{\circ} \mathrm{C}$. The oscillation sweep tests at $25{ }^{\circ} \mathrm{C}$ in an oscillation strain range from 0.1 to $100 \%$ and angular frequency of $10 \mathrm{rad}^{-\mathrm{s}^{-1}}$ were performed to determine the changes in mechanical loss $\tan \delta$ as a function of the applied deformation. The measurements of the storage shear modulus $G^{\prime}$ and loss shear modulus $G^{\prime \prime}$ were taken at $25^{\circ} \mathrm{C}$ at low oscillation strain $0.1 \%$ (linear viscoelastic region) and at $1 \%$ of oscillation strain in angular frequency range from 0.1 to $100 \mathrm{rad}^{-1} \mathrm{~s}^{-1}$. Additional frequency tests at $-5^{\circ} \mathrm{C}$ in angular frequency range from 0.1 to $100 \mathrm{rad}^{\prime} \mathrm{s}^{-1}$ at $0.02 \%$ of oscillation strain (linear viscoelastic region) were carried out.

\section{Measurements of cross-link density}

The network structure was analyzed according to ASTM D6814-02 standard. Weighted rubber samples were swollen at $25^{\circ} \mathrm{C}$ in solvent (reagent grade purity 
toluene) for the time necessary to achieve weight balance of swollen samples. The solvent was replaced with fresh toluene every $24 \mathrm{~h}$. After swelling, the excess of liquid was removed from the surface of samples with a soft paper towel and samples were weighted. Then, samples were dried at $50{ }^{\circ} \mathrm{C}$ in a forced-ventilating air oven for $24 \mathrm{~h}$ until constant mass. In the next step, the dried samples were cooled down to room temperature $\left(25^{\circ} \mathrm{C}\right)$ using a desiccator and weighted again. The samples were swollen in toluene in a desiccator with saturated ammonia vapor (25\% aqueous solution) at $25{ }^{\circ} \mathrm{C}$ to determine the content of the destroyed under basic treatment cross-links. The cross-link density for various MG-XNBR was estimated using the Flory-Rehner's equation [33]. The percentage of non-covalent cross-links (formed during curing $\left(\nu^{*}\right)$ was determined by decomposition of present ionic cross-links under the ammonia vapor treatment and it was calculated according to Eq. (9):

$$
v^{*}=\frac{v_{t}-v_{a}}{v_{t}} * 100 \%
$$

where $\nu_{\mathrm{a}}$ is the cross-link density determined for samples treated with ammonia, $\nu_{\mathrm{t}}$ is the cross-link density determined for samples swollen in toluene.

\section{Stress relaxation experiments}

Stress relaxation experiments were performed using Ares G2 rheometer equipped with parallel plate-plate geometry. The measurements were taken at $25^{\circ} \mathrm{C}$. A strain of $0.05 \%$ was kept constant during measurements. The stress monitoring started immediately after the required strain was attained. Relaxation curves were recorded during $1000 \mathrm{~s}$.

\section{Results and discussion}

\section{The influence of filler on the flow behavior, viscoelastic properties and processability of XNBR mixtures at processing temperature $\left(80^{\circ} \mathrm{C}\right)$.}

\section{Analysis of the complex viscosity of the material}

The analysis of viscosity of the material at processing temperature is one of the characteristics that allows to determine the processability of a given rubber compound [34]. The flow behavior at the processing temperature of $80{ }^{\circ} \mathrm{C}$ and the shear thinning properties were analyzed. The parameter such as the complex dynamic viscosity $\eta^{*}$ from the RPA rheometers, which is analogous to the apparent viscosity $\left(\eta_{\text {app }}\right)$ from the capillary rheometer [34], was measured under conditions of steady shear rate. Studied shear rate range was programmed using an applied constant strain (100\%) by increasing the frequency of the sinusoidal oscillation. Application of high strain more effectively destroys the filler aggregates, which are formed during rubber mixture storage. Additionally, these conditions are more comparable with the real conditions of processing. During high shear 
Fig. 1 Complex viscosity $\eta^{*}$ (kPa's) at $80^{\circ} \mathrm{C}$ (processing temperature) for $\mathrm{XNBR}$ mixtures containing various $\mathrm{MG}$ fillers

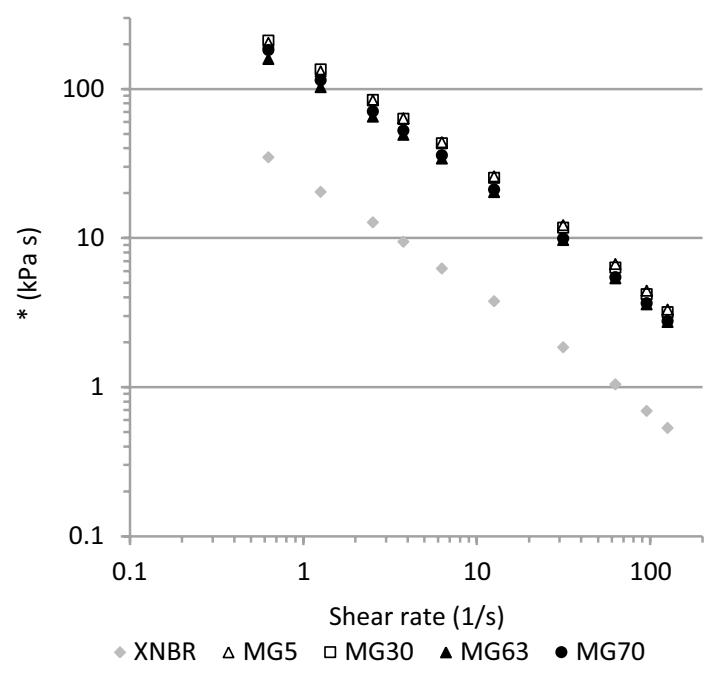

Table 1 Consistency index $K$, flow index $n$ and correlation coefficient $R^{2}$

\begin{tabular}{lcll}
\hline & $K \mathrm{kPas}$ & $n$ & $R^{2}$ \\
\hline XNBR & 25.8 & 0.217 & 0.998 \\
MG5 & 168.4 & 0.228 & 0.995 \\
MG30 & 172.2 & 0.207 & 0.996 \\
MG63 & 130.0 & 0.202 & 0.996 \\
MG70 & 144.4 & 0.219 & 0.997 \\
\hline
\end{tabular}

mixing or extruding, the material is subjected to relatively high deformations as compared to compression molding. Melt rubber compounds are non-Newtonian fluids and usually their viscosity decreases according to the power law model [34]. The increase in the initial viscosity of uncured rubber after addition of filler results from three facts: the hydrodynamic effect of the filler, the interactions between filler surface and polymer chains and the interactions among filler particles [35]. The influence of type of filler on the shear thinning behavior of XNBR compounds was analyzed (Fig. 1, Table 1). The observed variation of complex viscosity $\eta^{*}$ and its decrease with shear rate is typical for pseudoplastic materials. In the whole range of studied shear rates, MG5 and MG30-XNBR (Al-rich fillers) presented higher values of viscosity than MG63 and MG70-XNBR (Fig. 1). This fact is attributed to a stronger filler-filler interactions and larger surface area of both MG5 and MG30 fillers. According to our previous studies [14], the surface area of MG63 and MG70 (Mg-rich fillers) was much lower (MG63 $-200 \mathrm{~m}^{2} \cdot \mathrm{g}^{-1}$, MG70-196 $\mathrm{m}^{2} \cdot \mathrm{g}^{-1}$ ) than MG5 and MG30 (MG5 $250 \mathrm{~m}^{2} \cdot \mathrm{g}^{-1}$, MG30 $276 \mathrm{~m}^{2} \cdot \mathrm{g}$ ), as measured after activation (calcination) at $550{ }^{\circ} \mathrm{C}$ for $3 \mathrm{~h}$. Others studies showed [30] that also before calcination MG63 and MG70 fillers exhibited lower surface area comparing to MG30. The increase in this parameter resulted in the 
enhancement of the interphase contact between the solid surface and elastomer and thus had impact on the flow behavior at whole range of shear rate. Other filler property, which caused an increase in the initial viscosity, especially at a relatively low deformation rate $\left(<1 \mathrm{~s}^{-1}\right)$, it was the tendency to create "ownfiller-structure" in an elastomer via particle-particle interactions. Layered double hydroxides exhibit a strong tendency to aggregate due to electrostatic interactions and possibility to form hydrogen bonds. This tendency can be estimated on the basis of oil absorption parameters (OAPs). The void volume between aggregates and agglomerates connected together through physical interactions can be expressed as the volume of dibutyl phthalate (DBP) absorbed by a given mass of filler (g DBP per100g filler). Our previous studies [14] revealed the lower values of oil absorption parameters OAPs and weaker tendency to create "own-structure"

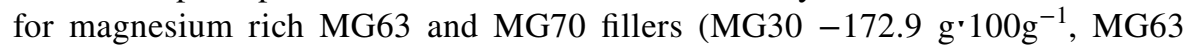
$-104.2 \mathrm{~g} \cdot 100 \mathrm{~g}^{-1}, \mathrm{MG} 70-86.5 \mathrm{~g} \cdot 100 \mathrm{~g}^{-1}$ ). The measured value of OAPs for MG5 $-140.1 \mathrm{~g} \cdot 100 \mathrm{~g}^{-1}$ indicated stronger tendency to create particles-particles interactions than these observed for MG63 and MG70, fillers with lower surface area and higher $\mathrm{Mg}$; $\mathrm{Al}$ ratio. The obtained values OAPs parameters confirmed that the complex viscosity $\eta^{*}$ of MG5-XNBR and MG30-XNBR compounds was slightly higher due to both: the larger surface area of fillers and the stronger filler-filler interactions between filler particles.

It is important not only to measure the viscosity but also to know how rapidly the viscosity is reduced with increasing shear rate. The consistency index $K$ related to the viscosity of the compound and the exponent of the potential equation $n$ were calculated. The values of both parameters are compiled in Table 1. The higher values of consistency indexes $K$ observed for MG5-XNBR and MG30-XNBR, can be explained by the facts described previously, the larger surface area and stronger tendency to form the ordered filler particles structure. The break-up of filler aggregates and re-orientation of the filler particles in the same direction, as the shear rate increased, resulted in higher value of flow index $n$ observed for the MG5-XNBR mixture.

\section{The viscoelastic properties of uncured composites at low and high deformation}

Rubber is a viscoelastic material, that possesses both viscous and elastic properties in melt, uncured and cured state. The elasticity of rubber mixtures before curing is mostly due to the chains entanglements. However, too low ratio of the viscous quality (loss modulus $G^{\prime \prime}$ ) to the elastic quality (storage modulus $G^{\prime}$ ) and too low values of loss factor $\tan \delta$ for the uncured rubber can influence on the material processing. The processes such as rubber mixing, the incorporation of fillers, forming the shape of final products, are affected by viscoelastic properties. Rubber mixtures with higher elasticity (higher values of storage modulus $G$ ') can resist processing leading to greater die swell during extrusion and poorer dimensional stability. Additionally, viscoelastic properties of elastomer materials containing nanofillers are strongly dependent on the size of the dispersed filler phase and its uniform distribution throughout the elastomer matrix. These effects are further magnified if additional interactions (polar, chemical, van der Waals interactions) occur 
at the polymer-filler interface. The reinforcing microphase between elastomer and filler surface may be formed resulting from polymer-filler interactions and occlusion of elastomer chains on the filler surface roughness. This process can take place even during mixing at lower temperature influencing the processing of rubber. The carboxylated nitrile rubber (XNBR) is an elastomer with carboxylic groups along chains, which are able to react with metal ions leading to the formation of ionic cross-links [6]. Higher Mg:Al ratio (MG63, MG70) gives the opportunity to form stronger interphase interactions with carboxylic groups present in elastomer chain. From the other hand, the larger contact area generated by higher values of surface area (MG5, MG30) also influences on the values of the storage shear modulus $G$ '. Certainly, the higher values of storage shear modulus $G^{\prime}$ observed for uncured MG5 and MG30-XNBR compounds resulted from the larger surface area and the stronger tendency to form aggregate-aggregate associations (Fig. 2). Differences in formed agglomerate-agglomerate network (filler network) were also responsible for higher values of the loss shear modulus $G^{\prime \prime}$ observed for MG5-XNBR and MG30-XNBR compounds (Fig. 3). The morphology of filler particles was another factor influencing on the elastic behavior of uncured XNBR compounds. Figure 2 reveals lower values of the storage shear modulus $G^{\prime}$ measured in linear viscoelastic region for the uncured MG63-XNBR comparing to MG70-XNBR compound. Effect was attributed to the various shape and morphology of particles of both filler. More agglomerated structure of MG63 was confirmed by optical microscopy study (Supplementary Material, Fig. A1). Higher platelet aspect ratio of MG70 filler was responsible for stronger polymer-filler interactions and increased values of $G^{\prime}$ modulus comparing to these observed for MG63-XNBR. It should be taken under consideration, that the filler-filler and filler-polymer interactions can be competitive in certain way for the active fillers [35]. The higher temperature $80{ }^{\circ} \mathrm{C}$ can promote the mobility of elastomer chains facilitating the adsorption of polymer chain on the filler surface

Fig. 2 Storage shear modulus $G^{\prime}(\mathrm{kPa})$ of uncured rubber mixtures XNBR at $80^{\circ} \mathrm{C}$ as a function of angular frequency $\omega\left(\operatorname{rad}^{\prime} \mathrm{s}^{-1}\right)$ (linear viscoelastic region)

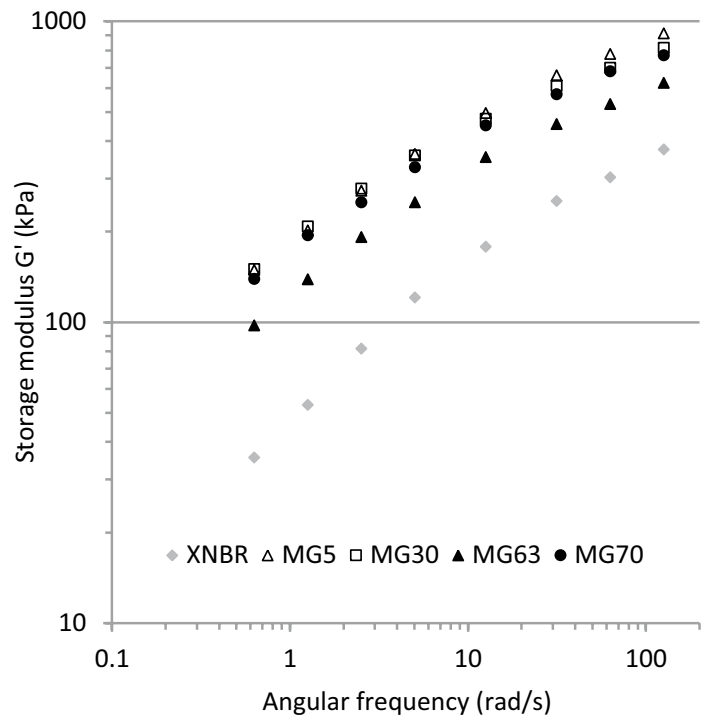


Fig. 3 Loss shear modulus $G^{\prime \prime}(\mathrm{kPa})$ of uncured rubber mixtures $\mathrm{XNBR}$ at $80{ }^{\circ} \mathrm{C}$ as a function of angular frequency $\omega\left(\operatorname{rad}^{\prime} \mathrm{s}^{-1}\right)$ (linear viscoelastic region)

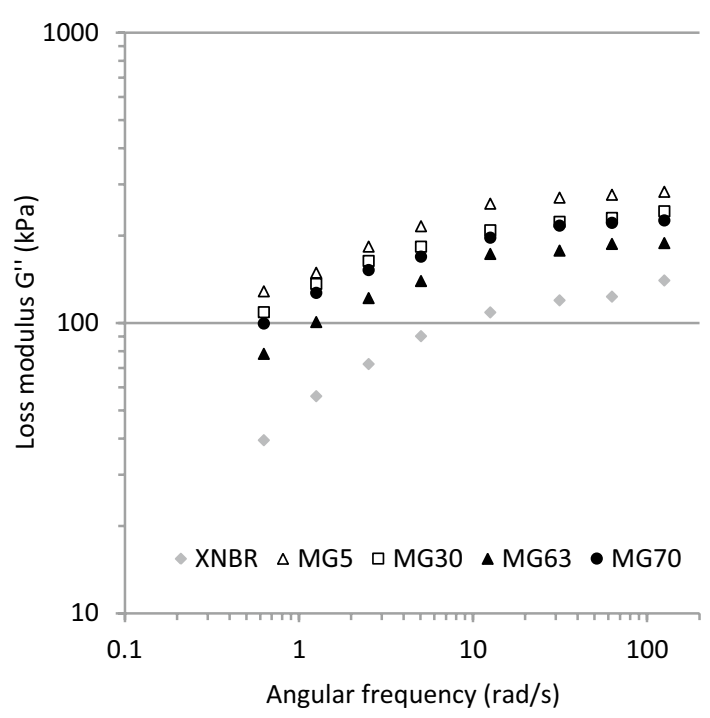

(occluded rubber) and preventing the filler-filler network formation. The amount of polymer chains adsorbed on the filler surface having restricted mobility is mainly affected by filler's concentration (similar for all studied rubber mixtures), the area of interphase contact (the surface area, platelet aspect ratio) and the surface chemistry (Mg:Al ratio). As Fig. 4 shows, the values of $\tan \delta$ for the angular frequency $\omega$ lower than $1 \mathrm{rad}^{-1} \mathrm{~s}^{-1}$ (longer relaxation time) significantly varied for MG30 and MG70XNBR compounds as compared to MG5 and MG63-XNBR. The higher amount of polymer chains with restricted mobility (occluded rubber) and the strength of polymer-filler interactions influenced on the relaxation of melt MG30 and MG70-XNBR

Fig. 4 The mechanical loss tan $\delta(-)$ as a function of angular frequency $\omega\left(\operatorname{rad}^{\prime} \mathrm{s}^{-1}\right)$ (linear viscoelastic region)

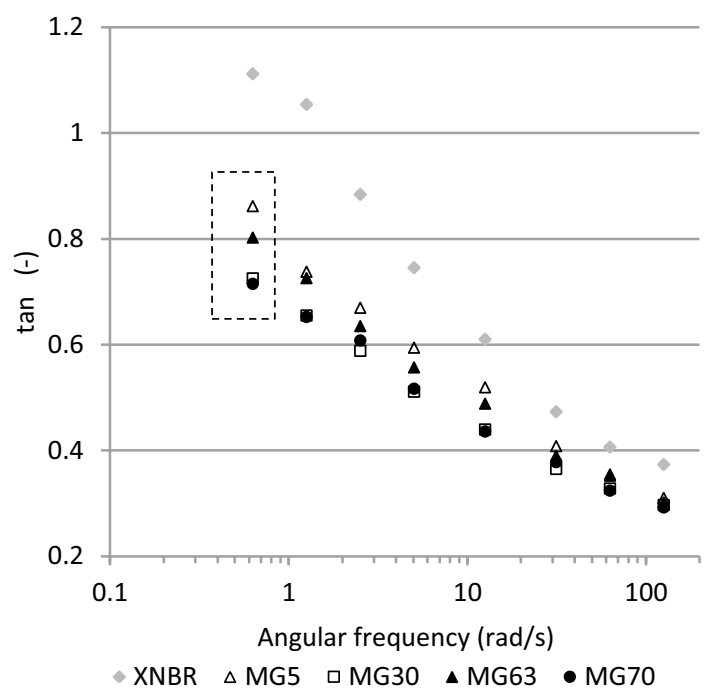


compound in linear viscoelastic region leading to lower values of the loss factor tan $\delta$.

To estimate the influence of formed filler-filler associations on the viscoelastic properties, the storage shear $G^{\prime}$, the loss shear modulus $G^{\prime \prime}$ and the values of $\tan \delta$ were measured in function of angular frequency $\omega$ applying high values of oscillation strain $(100 \%)$, equivalent of $0.6-125 \mathrm{~s}^{-1}$ oscillation shear rate for studied angular frequency range. The high strain leads to the break-up of filler aggregates and changes in the orientation of filler particles resulting in changes of viscoelastic properties. Additionally, high deformation can cause the slippage of loosely bonded polymeric chains from the surface of filler reducing amount of occluded rubber, which is shielded from deformation. At high applied strain, the hydrodynamic effect connected with the surface area and the aspect ratio of the particles should be dominant. At these conditions, the enhancement of the storage shear modulus $G^{\prime}$ should be in accordance with the measured values of the surface area. Above explanations were confirmed by the results of viscoelastic properties measurements (Supplementary Material, Fig. A2-A3). The larger surface area of incorporated filler generated stronger enhancement of the storage shear modulus $G^{\prime}$ of XNBR compound. For all uncured XNBR compounds under this conditions (100\% of oscillation strain), the cross-points of both modulus $\left(G^{\prime}=G^{\prime \prime}, \tan \delta=1\right)$ were found indicating that from some values of angular frequencies (equivalent of some shear rate) the viscous behavior of melt rubber compound was dominant (Fig. 5). The cross point for MG5 occurred at slightly higher value of frequency (MG5 -3.9 $\mathrm{rad}^{-1} \mathrm{~s}^{-1}$, MG30 $-1.6 \mathrm{rad}^{\prime} \mathrm{s}^{-1}$, MG63 -1.4 $\mathrm{rad}^{-1} \mathrm{~s}^{-1}$, MG70 -1.5 $\mathrm{rad}^{-1}{ }^{-1}$ ) (Fig. 5). For the measurement at linear viscoelastic region the cross point was observed only for pure melt XNBR (Fig. 4). Analyzing the influence of high deformation on the processability of rubber, it should be noted that for high frequency and short times of relaxation (equivalent of $125 \mathrm{~s}^{-1}$ shear rate, typical for the extrusion processes), only the MG5-XNBR compound exhibited similar $\tan \delta$ values as neat rubber. For other

Fig. 5 Mechanical loss $\tan \delta$ $(-)$ as a function of angular frequency $\omega\left(\mathrm{rad}^{-\mathrm{s}^{-1}}\right)$ (oscillation strain $100 \%$ )

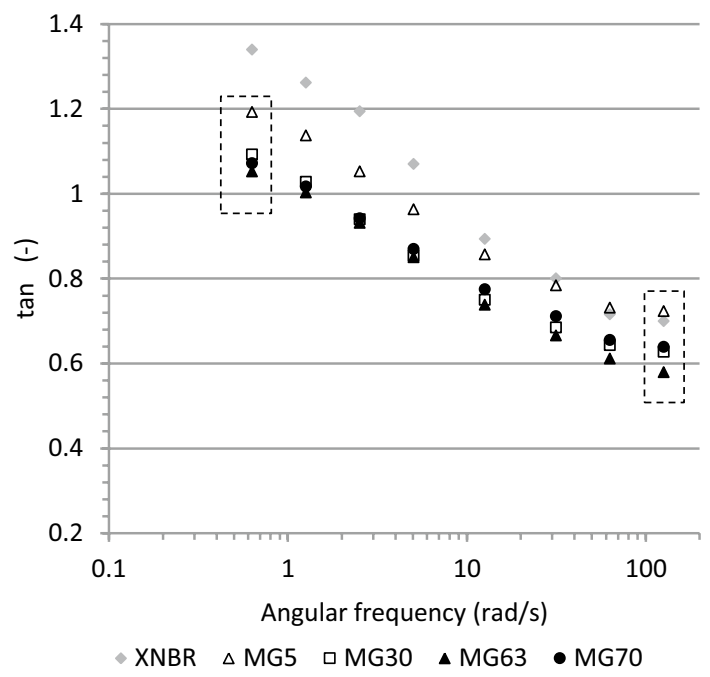


MG-XNBR compounds, lower values of mechanical loss tan $\delta$ were observed indicating worse processability. The decrease in the storage shear modulus $G^{\prime}$ observed after application of high deformation confirmed that one of the factors, that had strong impact on the viscoelastic behavior, was the tendency to form particles-particles associations. These associations were easily destroyed at high deformation conditions. Additionally, the analysis of cross-points and the observed lower values of $\tan \delta$ suggested that at this temperature conditions $\left(80^{\circ} \mathrm{C}\right)$ for $\mathrm{MG}$ fillers with higher amount of $\mathrm{Mg}^{2+}$ ions some ionic pairs were formed. These ion pairs influenced on the processability and relaxation behavior of rubber compound, at high frequency. Taking into account the assumption that during processing at $80{ }^{\circ} \mathrm{C}$, the formation of some ionic pairs may partially occur, in the next paragraph the kinetic of crosslinking reaction and its dependence on the type of MG filler is analyzed.

\section{The influence of MG filler characteristic on curing at various temperatures}

In the literature, various techniques are applied to investigate the kinetic of curing, among them FTIR spectroscopy [36] and the differential scanning calorimetry DSC [37]. The RPA rheometers allow to study the cure kinetic of rubber mixtures, together with the viscoelastic properties during curing [38]. First, the differential scanning calorimetry (DSC) was applied to estimate the temperature of XNBR ionic curing. The DSC curves are shown in Supplementary Material (Fig. A4-A7). From the exothermic peaks, the range of curing temperatures as the onset, endset temperatures and the temperature at the maximum of peak were determined. The glass transition temperatures of uncured rubber compounds $T_{\mathrm{g}}$ and the range of curing temperatures are compiled in Table 2. The glass transition temperatures $T_{\mathrm{g}}$ of uncured XNBR-compounds containing $\mathrm{MG}$ fillers with higher amount of $\mathrm{Mg}^{2+}$ (MG63, MG70) were slightly shifted to higher values of temperature comparing with MG5-XNBR compound. This confirmed that for the MG63 and MG70 fillers during preparation of XNBR mixtures the stronger and more stable interphase interactions appeared. Higher amount of immobilized rubber with restricted mobility was formed on the filler surface even before the ionic curing of rubber. Prior research [39] indicated that the differential heat capacity $\left(\Delta c_{\mathrm{p}}\right)$ is directly proportional to the amount of the polymer that undergoes this transition. The results reported in Table 2

Table 2 Glass transition temperatures $T_{\mathrm{g}}\left({ }^{\circ} \mathrm{C}\right)$, the enthalpy change of curing $\Delta H\left(\mathrm{~J}^{\prime} \mathrm{g}^{-1}\right)$

\begin{tabular}{lllll}
$T_{\mathrm{g}},{ }^{\circ} \mathrm{C}$ & $\Delta c_{\mathrm{p}}, \mathrm{Jg}^{-1} \mathrm{~K}^{-1}$ & $\Delta H, \mathrm{Jg}^{-1}$ & $\begin{array}{l}\text { Temperature at maximum } \\
\text { of the peak, }{ }^{\circ} \mathrm{C}\end{array}$ & $\begin{array}{l}\text { Curing } \\
\text { temperatures, } \\
{ }^{\circ} \mathrm{C}\end{array}$ \\
\hline-25.9 & 0.501 & 3.30 & 186 & $150-247$ \\
-24.3 & 0.452 & 4.02 & 192 & $136-223$ \\
-23.3 & 0.433 & 8.11 & 150 & $90-184$ \\
-22.9 & 0.378 & 8.57 & 163 & $88-187$ \\
\hline
\end{tabular}

The differential heat capacity $\Delta c_{\mathrm{p}}\left(\mathrm{Jg}^{-1} \mathrm{~K}^{-1}\right)$, temperature at the maximum of exothermic peak and the range of curing temperature $\left({ }^{\circ} \mathrm{C}\right)$ for uncured MG-XNBR compounds 
indicated that the values of the heat capacity $\Delta c_{\mathrm{p}}$ of the investigated samples containing MG fillers decreased slightly with the increase in magnesium amount in filler structure. This also confirmed the differences in the amount of immobilized polymer chains. The behavior and the structural mobility of the MG-XNBR within the temperature of the glass transition was changed as the $\mathrm{Mg}$; $\mathrm{Al}$ ratio increased. Curing of XNBR compound by MG fillers was one-step exothermic process, which occurred in various temperature range as the $\mathrm{Mg}$ : $\mathrm{Al}$ ratio changed. The lower amount of $\mathrm{Mg}^{2+}$ ions (MG5, MG30) significantly shifted the onset curing temperature toward higher temperature. Therefore, it was concluded from the DSC studies that the activity of MG fillers with various $\mathrm{Mg}$ :Al ratio was strongly depended on the temperature of curing. It should be taken into account that the optimal curing temperature for $\mathrm{MG}$ fillers with predominance of $\mathrm{Al}$ over $\mathrm{Mg}$ (MG5, MG30) was higher $\left(180^{\circ} \mathrm{C}\right)$ than for these with predominance of $\mathrm{Mg}$ over $\mathrm{Al}$ in structure (MG70) $\left(160{ }^{\circ} \mathrm{C}\right.$ ). Moreover, the beginning of curing for MG63 and MG70 fillers started at approximately $80-90^{\circ} \mathrm{C}$, that confirmed our previous observations. Some ionic immobilized phase was formed during processing. Higher values of the enthalpy change of curing and the higher amount of heat evolved in the transformation of the reactants for MG63 and MG70-XNBR confirmed that the curing reactions led to the formation of interfacial bonds with greater intensity. Based on DSC studies, the temperature range for RPA kinetic studies was estimated $\left(140-180^{\circ} \mathrm{C}\right)$.

Regarding the increase in the normalized elastic component $\Delta S^{\prime}$ as a function of time (Table 3), usually calculated based on the vulcanization curves (Supplementary Material, Fig. A8-A9), every filler was able to form cross-links during curing at the temperature of $160-180{ }^{\circ} \mathrm{C}$. The increase in the normalized elastic component $\Delta S^{\prime}$ lower than $1 \mathrm{dNm}$, observed for the MG5-XNBR at $140-150{ }^{\circ} \mathrm{C}$ and for MG30-XNBR at $140{ }^{\circ} \mathrm{C}$ indicated that at this temperature conditions the formation of cross-links did not occurred. These observations were in accordance with DSC studies pointing out that for fillers with lower $\mathrm{Mg}$ : $\mathrm{Al}$ ratio the higher temperatures are needed to achieve a satisfactory progress of curing reactions. The formation of ionic cross-links was time dependent. It was observed that at any temperature, the $\Delta S^{\prime}$ curves raised with reaction time. Moreover, regarding the rate of cure, during first $30 \mathrm{~min}$, at $160{ }^{\circ} \mathrm{C}$, the MG70 filler enhanced the increase in the elastic component $S^{\prime}$ comparing to other fillers. The acceleration of the reaction during first stage of curing may be achieved by the increase in the temperature. As it was observed for MG30 and MG63-XNBR compound after increase in curing temperature from $160{ }^{\circ} \mathrm{C}$ to $180{ }^{\circ} \mathrm{C}$ (Supplementary Material, Fig. A8-A9).

In Table 3 are compiled calculated parameters such as: the rate constant $K$, $\mathrm{n}$-order of reaction and the apparent activation energy $\mathrm{E}_{\mathrm{a}}$. The lower calculated values of the apparent energy of activation $E_{\mathrm{a}}$ confirmed that the amount of $\mathrm{Mg}$ present in filler structure had the catalytic effect on XNBR curing (Table 3). The calculated values of the rate constant $K$ and n-order of reaction revealed that the process mechanism for every filler was affected by temperature. Raising temperature of curing caused an increase in the reaction speed, as confirmed by higher values of the rate constant $K$, together with the decrease in the n-order of reaction. Moreover, it was observed that the rate constant $\mathrm{K}$ related to a particular factual mechanism occurring at chosen temperature (e.g., $160{ }^{\circ} \mathrm{C}$ ) were dependent 
Table 3 The minimum values of elastic torque $S_{\text {min }}^{\prime}$

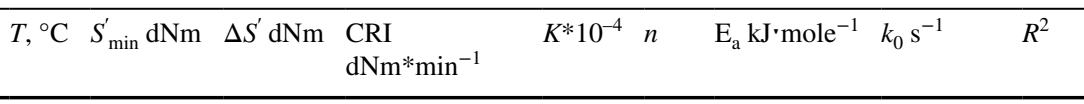

\begin{tabular}{llllllllll}
\hline MG5 & 140 & $*$ & $*$ & $*$ & $*$ & $*$ & 203.27 & $3.63 \mathrm{E}+20$ & 0.995 \\
& 150 & $*$ & $*$ & $*$ & $*$ & $*$ & & & \\
& 160 & 1.18 & 1.34 & 0.10 & 1.063 & 1.24 & & & \\
& 170 & 0.94 & 1.55 & 0.15 & 4.407 & 1.07 & & & \\
& 180 & 0.85 & 2.26 & 0.21 & 12.806 & 0.92 & & & \\
MG30 & 140 & $*$ & $*$ & $*$ & $*$ & $*$ & 185.76 & $2.97 \mathrm{E}+18$ & 0.999 \\
& 150 & 1.86 & 3.42 & 0.17 & 0.349 & 1.34 & & & \\
& 160 & 1.46 & 4.54 & 0.23 & 1.183 & 1.23 & & & \\
& 170 & 1.31 & 5.61 & 0.42 & 3.723 & 1.12 & & & \\
& 180 & 1.12 & 5.53 & 0.57 & 11.562 & 1.03 & & & \\
MG63 & 140 & 1.33 & 2.72 & 0.19 & 0.086 & 1.52 & 159.16 & $1.14 \mathrm{E}+15$ & 0.997 \\
& 150 & 1.19 & 3.60 & 0.17 & 0.283 & 1.36 & & & \\
& 160 & 1.21 & 4.98 & 0.24 & 0.638 & 1.35 & & & \\
& 170 & 0.93 & 5.43 & 0.34 & 2.001 & 1.21 & & & \\
& 180 & 0.99 & 6.92 & 0.45 & 5.414 & 1.29 & & & \\
MG70 & 140 & 3.06 & 3.97 & 0.58 & 3.857 & 0.88 & 111.46 & $5.25 \mathrm{E}+11$ & 0.993 \\
& 150 & 2.39 & 4.09 & 1.09 & 10.565 & 0.79 & & & \\
& 160 & 2.87 & 4,56 & 1.44 & 18.108 & 0.71 & & & \\
& 170 & 2.56 & 4,44 & 2.34 & 40.288 & 0.63 & & & \\
& 180 & 2.04 & 4,68 & 3.21 & 70.461 & 0.56 & & & \\
\hline
\end{tabular}

The increase in the elastic torque during curing $\Delta S^{\prime}$, cure rate CRI and calculated kinetic parameters for $\mathrm{Mg}-\mathrm{Al}-\mathrm{LDH}-\mathrm{XNBR}$ compounds

* - at this temperature condition the formation of crosslinks did not occured

on the type of filler incorporated into XNBR. Similarity of the kinetic parameters, such as the rate constant and the n-order of reaction was observed for aluminumrich fillers (MG5, MG30). It suggested that the changes in $\mathrm{Mg}^{2+}: \mathrm{Al}^{3+}$ ratio did not influenced significantly on the reaction mechanism for both filler. This trend could be attributed to much larger specific surface area and the porosity of both filler increasing the possibility for the interaction with the rubber chains. Probably, in this case, the active cation sites on the filler surface and hydroxyl groups were more easily accessible resulted in higher values of the rate constant $K$ than these observed for MG63 filler. However, it should be underlined that the lower amount of magnesium in the structure of both filler had an impact on the temperature range of curing. Also the efficiency of curing understood as an increase in the value of the normalized elastic component $\Delta S^{\prime}$ was lower. The curing reaction between XNBR and MG70 filler was characterized by the rate constants $K$ of a higher order than it was observed for other MG fillers. Moreover the much lower values of $\mathrm{n}$-order of reaction (lower than 1 for every investigated temperature), as compared to the previously described aluminum-rich fillers (MG5, MG30) and 
the magnesium rich MG63 filler, suggested different mechanism of reaction. The order of reaction [40] refers to the power dependence of the rate on the concentration of each reactant in this case: carboxylic groups $-\mathrm{COOH}$ present in XNBR and curing substance, cations $\mathrm{Mg}^{2+}: \mathrm{Al}^{3+}$ provided by $\mathrm{Mg}-\mathrm{Al}-\mathrm{LDH}$ filler. Thus, a first-order reaction refers to one whose rate is dependent on the concentration of a single species. Experimentally determined order of reaction can take on a fractional value. For simple one-step reaction, the order and the stoichiometry of the reaction (the theoretical integer value of the number of molecules involved in the reaction) should be similar. It is obvious that the curing of XNBR by Mg-Al$\mathrm{LDH}$ is more complicated than one step reaction occurring between $\mathrm{Mg}^{2+}$ cations and carboxylic groups of XNBR. The cross-linking of XNBR by Mg-Al-LDH can take place through both (a) polar interactions between the functional groups of XNBR $(-\mathrm{CN},-\mathrm{COOH})$ and basic hydroxyl groups on the surface of LDH, and (b) the formation of ionic cross-links between the carboxylic groups and metal ions provided by Mg-Al-LDH. Higher amount of magnesium in MG70-LDH promoted the formation of more ordered ionic phase with higher amount of ionic clusters resulted in the lower apparent activation energy $E_{\mathrm{a}}$ of the process. The larger palettes aspect ratio and smaller size of the MG70 particles increased interphase area between rubber and filler enhancing the accessibility to the active sites on the filler surface. These factors caused that the formation of ionic clusters for MG70-XNBR was more favorable and the reaction occurred with higher rate constant $\mathrm{K}$ and lower order of reaction. The agglomerated structure of the magnesium rich MG63 filler, the lower aspect ratio of the particles led to restricted accessibility to the active cationic sites resulting in lower values of rate constant $K$ of curing.

To confirm better activity of MG5 and MG30 during curing at higher temperature $180{ }^{\circ} \mathrm{C}$, the storage shear modulus $G^{\prime}$ was investigated at $100{ }^{\circ} \mathrm{C}$ directly after curing at $140{ }^{\circ} \mathrm{C}$ and $180^{\circ} \mathrm{C}$ using RPA rheometer (Supplementary Material, Fig. A10). As we expected, curing at higher temperature $180{ }^{\circ} \mathrm{C}$ significantly enhanced the values of the storage shear modulus of MG30-XNBR compound due to the formation of filler-rubber interactions and ionic cross-links. The effect of temperature was not observed for MG63 and MG70-XNBR (Supplementary Material, Fig. A10). The values of the storage shear modulus $G^{\prime}$ after curing at $140{ }^{\circ} \mathrm{C}$ were as follows: MG63 $-1267 \mathrm{kPa}$ (1\% oscillation strain); MG70 $1326 \mathrm{kPa}\left(1 \%\right.$ oscillation strain), after curing at higher temperature $180{ }^{\circ} \mathrm{C}$ the modulus changed as follows: MG63 $-1273 \mathrm{kPa}$ (1\% oscillation strain); MG70 $-1368 \mathrm{kPa}$ (1\% oscillation strain). Slight increase in the modulus observed for MG63 and MG70-XNBR after curing at higher temperature $180{ }^{\circ} \mathrm{C}$ confirmed our previous statement that the formation of ionic cross-links occurred at whole studied temperature range $140-180{ }^{\circ} \mathrm{C}$. For both MG5 and MG30-XNBR compounds cured at $180{ }^{\circ} \mathrm{C}$, the filler-filler structure was formed in higher extent comparing to MG70-XNBR. Significant decrease in the modulus was observed after first cycle of deformation (Supplementary Material, Fig. A11). The decrease in the values of $G^{\prime}$ after first cycle of deformation was as follows: MG5 -95 kPa, MG30 -230 kPa, MG63 -23 kPa, MG70 -29 kPa. 


\section{Influence of $\mathrm{Mg}$-Al-LDHs on the glass transition temperature $T_{g}$, the ionic transition temperature $T_{\alpha^{\prime}}$ of XNBR and the amount of the ionic cross-links formed.}

The temperature $180{ }^{\circ} \mathrm{C}$ was chosen as a curing temperature. To further investigate the viscoelastic properties of $\mathrm{Mg}-\mathrm{Al}-\mathrm{LDHs}-\mathrm{XNBR}$, the glass transition temperature $T_{\mathrm{g}}$ of cured rubber was analyzed. The spectra of $\tan \delta$ for MG-XNBR are depicted in Fig. 6. The peak of mechanical loss $\tan \delta$ attributed to intense $\alpha$ relaxation transition and the changes in the segmental movements was observed in the lower temperature region indicating the glass transition temperature $T_{\mathrm{g}}$. of XNBR. As we expected, the application of MG-AL-LDHs as curing substances of XNBR instead of sulfur curing system led to formation of cured vulcanizates with lower $T_{\mathrm{g}}$ values. The segmental movement and the structural mobility of the rubber matrix containing chemical sulfur bond were much restricted comparing with the ordered ionic phase. As it can be seen from Fig. 6 and Table 4, the glass transition temperatures $T_{\mathrm{g}}$ of studied ionic cured XNBR were similar. The values of $T_{\mathrm{g}}$ were shifted to higher values of temperature than these determined by DSC for uncured XNBR compounds (Table 2). This confirmed the formation of cross-links with restricted mobility of rubber chains during curing. Analyzing the heights of $\tan \delta$ peak it should be noted that incorporation of MG63 and MG70, magnesium rich LDHs, into XNBR decreased the height of $\tan \delta$ peak comparing with these containing aluminum-rich fillers. The intensity of the relaxation transition of the soft segments (height of the $\tan \delta$ peak at glass transition temperature $T_{\mathrm{g}}$ ) was more pronounced for aluminum-rich MG5-XNBR

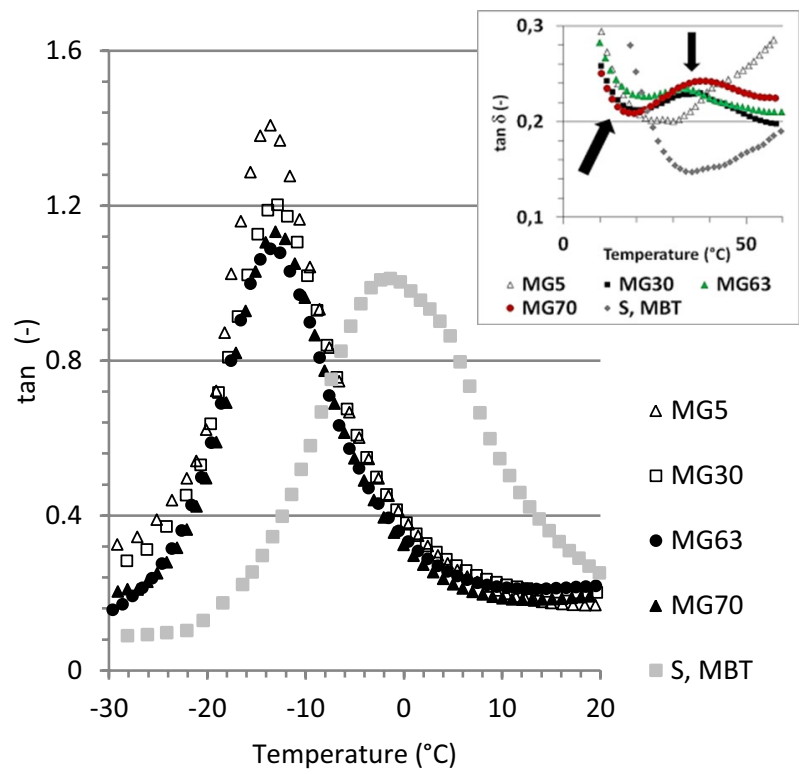

Fig. 6 Mechanical loss tangent $\tan \delta(-)$ versus temperature for Mg-AL-LDH-XNBR compounds. Small picture in the right corner exhibited the $\tan \delta$ of $\alpha^{\prime}$ relaxation process of ionic hard phase 
Table 4 Glass transition temperature $T_{\mathrm{g}}$, Ionic transition temperature $T_{\alpha^{\prime}}$, the height of $\tan \delta$ peaks, crosslink density calculated from the swelling measurements in toluene $\nu_{\mathrm{t}}$ and the percentage of the destroyed cross-links under basic treatment $\Delta \nu$ for $\mathrm{Mg}-\mathrm{Al}-\mathrm{XNBR}$ compounds

\begin{tabular}{llllllll}
\hline & $T_{\mathrm{g}},{ }^{\circ} \mathrm{C}$ & $\begin{array}{l}\text { Height of } \tan \\
\delta \text { at } T_{\mathrm{g}}\end{array}$ & $T_{\alpha^{\prime}},{ }^{\circ} \mathrm{C}$ & $\begin{array}{l}\text { Height of tan } \\
\delta \text { at } T_{\alpha^{\prime}}\end{array}$ & $\begin{array}{l}\nu_{\mathrm{t}} \times 10^{5}, \\
\mathrm{~mole} / \mathrm{dm}^{3}\end{array}$ & $\Delta \nu(\%)$ & $\nu_{\mathrm{a}} / \nu_{\mathrm{t}}$ \\
\hline MG5 & -13.59 & 1.408 & - & - & 3.6 & 12.0 & 0.89 \\
MG30 & -13.37 & 1.202 & 36.92 & 0.229 & 9.3 & 40.6 & 0.59 \\
MG63 & -13.60 & 1.089 & 32.95 & 0.235 & 4.9 & 54.1 & 0.45 \\
MG70 & -13.08 & 1.133 & 37.90 & 0.242 & 14.0 & 48.0 & 0.52 \\
S, MBT & -1.92 & 1.013 & - & - & 23.9 & 16.4 & 0.84 \\
\hline
\end{tabular}

comparing with other $\mathrm{Mg}-\mathrm{Al}-\mathrm{LDHs}-\mathrm{XNBR}$. The results indicated that the weak interphase interactions between polymer chains and surface of the MG5 filler were present in XNBR composite.

Because of the labile character of ionic cross-links, it was possible to detect the changes in the relaxation transition of the ordered ionic phase ( $\alpha^{\prime}$ relaxation) [41]. This transition generated a maximum in the $\tan \delta$ at $T_{\alpha^{\prime}}$. A second maximum $(\alpha$ relaxation) was detected at a temperature of above $30{ }^{\circ} \mathrm{C}$ (Fig. 6). The second peak of loss tangent $\tan \delta$ resulted from the relaxation transition of the ordered ionic structure containing ion pairs as well as nonionic hydrocarbon content (segments of polymer chain) "trapped" in ionic structure. Significant differences were found in determined ionic transition peaks of MG-XNBR. The ionic cluster relaxation was not observed for MG5-XNBR. During curing of MG5-XNBR, the small amount of ionic cross-links with low number of ion pairs, statistically dispersed in hydrocarbon, was formed. The observed increase in $\tan \delta$ as the temperature rose above $30{ }^{\circ} \mathrm{C}$ resulted from the plasticizing and melting of rubber. The reported height of $\tan \delta$ at $T_{\alpha^{\prime}}$ increased as the amount of magnesium in filler structure rose (Table 4). The amount of magnesium played a significant role in the ionic phase formation and its relaxation transition. The peak observed for MG63-XNBR was narrowed and shifted to lower temperature $\left(32.95^{\circ} \mathrm{C}\right)$ comparing with MG70-XNBR $\left(37.90{ }^{\circ} \mathrm{C}\right)$ or MG30-XNBR $\left(36.92{ }^{\circ} \mathrm{C}\right)$. This pointed out that the formed ionic network present in MG63-XNBR was different comparing with the ionic phase formed for MG30 and MG70-XNBR.

The conclusions from analysis of Fig. 6 were confirmed by the results of crosslink density measurements (Table 4). The formed ionic clusters between metal ions and the carboxyl groups of rubber were easily destroyed under ammonia treatment. The percentage of this type of cross-link and the total cross-link density calculated from swelling in toluene were significantly lower in case of MG5-XNBR. This confirmed that aluminum ions were less or not active during curing. The higher amount of magnesium ions in filler structure was needed to form ionic phase. The obtained cross-link density results were in agreement with the observations from kinetic studies. The activation energy of the process decreased as the magnesium amount in filler structure increased. Taking into consideration that all samples were cured at $180{ }^{\circ} \mathrm{C}$ during the same time $(60 \mathrm{~min}$.) the achieved lower state of cure 
and lower values of total cross-link density of MG63-XNBR confirmed the observations from kinetic studies concerning the lower rate constant at $180{ }^{\circ} \mathrm{C}$ calculated for MG63-XNBR. Moreover, both MG30 and MG70-XNBR exhibited almost similar values of $\nu_{\mathrm{a}} / \nu_{\mathrm{t}}$ parameter, opposite to lower value observed for MG63-XNBR. The amount of ionic associations destroyed under more aggressive conditions (ammonia vapor) $\Delta \nu$ was lower for MG30 and MG70-XNBR. The much lower cross-link density of MG63-XNBR, together with the higher amount of ionic associations easily destroyed indicated less compacted ionic phase, with a low number of ion pairs. These observations were in accordance with the studies of the relaxation transition of formed ionic phase. The ionic transition peak of MG63-XNBR occurred at lower temperature $T_{\alpha^{\prime}}$ and the increase in $\tan \delta$ at $T_{\alpha^{\prime}}$ was lower comparing with MG30 and MG70-XNBR. Additionally, the ATR-FTIR analysis (Supplementary Material, Fig. A12-A13, Table A2) confirmed the formation of ionic bonds. The peaks at $1697 \mathrm{~cm}^{-1}$ (a stretching vibration of hydrogen bonded acid dimmers of carboxylic acid groups) and the second one at $1730 \mathrm{~cm}^{-1}$ (carbonyl stretching of monocarboxylic acid) decreased. The new peaks in the region of $1610-1580 \mathrm{~cm}^{-1}$ appeared for MG30, MG63 and MG70-XNBR. These peaks were attributed to stretching vibration of $>\mathrm{C}=\mathrm{O}$ in carboxylate ions $\left(-\mathrm{CO}-\mathrm{O}^{-}\right)$such as: $1610 \mathrm{~cm}^{-1}$ carbonyl stretching vibration of magnesium carboxylate salt, $1582 \mathrm{~cm}^{-1}$ asymmetric carbonyl stretching vibration of magnesium carboxylate salt. According to Krzemińska et al. [9], such ions may be formed during cross-linking with metal cations via - $\mathrm{COOH}$ groups from XNBR. Other authors [26] also reported the formation of new band at $1583 \mathrm{~cm}^{-1}$ corresponding to the $\mathrm{C}=\mathrm{O}$ stretching vibration of metal carboxylate salt. It can be assumed that the ionic cross-linking occurred with the $-\mathrm{COOH}$ groups but the structure of clusters differed as the Mg:Al ratio changed. For MG5 filler, no new peaks were observed confirming that the formation of ordered ionic bonds did not occurred. The intensities of peaks attributed to the stretching vibrations of monocarboxylic acid and $\mathrm{H}$-bonded $-\mathrm{COOH}$ group decreased less intensively for aluminum-rich filler MG30-XNBR, however the peaks indicating carboxylate ions were observed. It is worth noted that the formation of new ionic bands occurred in higher extent for the magnesium rich MG70 filler. The ionic structure in this case contained ionic network nodes together with ionic clusters formed by the aggregation of ionic groups. Spectrum of MG63-XNBR revealed the presence of the broadband in the range of $3200-3700 \mathrm{~cm}^{-1}$ corresponding to symmetric stretching $\left(\nu_{\mathrm{s}}\right.$ $\mathrm{O}-\mathrm{H}$ ) in hydroxyl groups. Moreover, the band at $1365 \mathrm{~cm}^{-2}$ appeared indicating the presence of interlayer carbonate anion in MG63 structure. This can be attributed to more agglomerated structure of the filler in elastomer matrix.

\section{The influence of MG fillers on the viscoelastic properties of cured XNBR}

This section discusses the influence of different filler structures on the viscoelastic properties of cured XNBR compound. The enhancement of the mechanical properties of $\mathrm{Mg}-\mathrm{Al}-\mathrm{LDH}-\mathrm{XNBR}$ most likely originated from the direct chemical interactions between the carboxylic groups of XNBR and metal ions present in $\mathrm{Mg}-\mathrm{Al}$-hydroxides. The ability to form ionic cross-links was reflected in the higher 
enhancement of the storage shear modulus $G^{\prime}$ as the ratio $\mathrm{Mg}$ :Al rising (Fig. 7). In this regard, the incorporation of the magnesium rich MG70 allowed to obtain reversible cured ionic elastomer with similar values of storage shear modulus (elasticity) as observed for conventionally cured by sulfur and MBT XNBR. Here, we must discuss more critically the obtained results and the reinforcing activity of the $\mathrm{Mg}-\mathrm{Al}-$ LDHs fillers. The reinforcing effect for ionic elastomer, in opposite to conventional sulfur cross-links, is connected with the formation of ordered ionic structure in form of large aggregates containing higher amount of ion pairs as well as trapped nonionic hydrocarbon content [42]. Thus, the properties of ionic elastomers are strongly dependent of the strength of ionic clusters formed and their distribution throughout matrix [7, 15, 17]. As we described in the previous section, the ionic transition temperatures were observed for the magnesium rich $\mathrm{Mg}-\mathrm{Al}$-fillers. Therefore, the presence of ionic phase was responsible in higher extent for the enhancement of the storage shear modulus $G^{\prime}$ as compared with MG5-XNBR containing aluminum-rich filler (Fig. 7). Similar to the Payne's model [43], the strain-independent part of the modulus was observed at low oscillation strain for all XNBR (Fig. 7). Opposite to sulfur cured rubber the linear viscoelastic region, in which the viscoelastic behavior of rubber is not affected by the deformation, extended to lower values of strain. The polymer chains movement upon straining was facilitated. The strong decrease in values of shear modulus, observed for $\mathrm{Mg}-\mathrm{Al}$-hydroxides-XNBR above the $10 \%$ of oscillation strain, resulted from both: the destruction of ionic clusters and pulling out the trapped chains from the ion phase, and the destruction of other type interactions, e.g., filler-filler interactions or polymer-filler interactions. It should be underlined, that the basic hydroxyl groups present in $\mathrm{Mg}-\mathrm{Al}$ hydroxides structures enhance their potential to form filler-filler structure. Additionally, the strong polar interactions between the polar $-\mathrm{CN}$ groups of XNBR and basic $-\mathrm{OH}$ functionalities
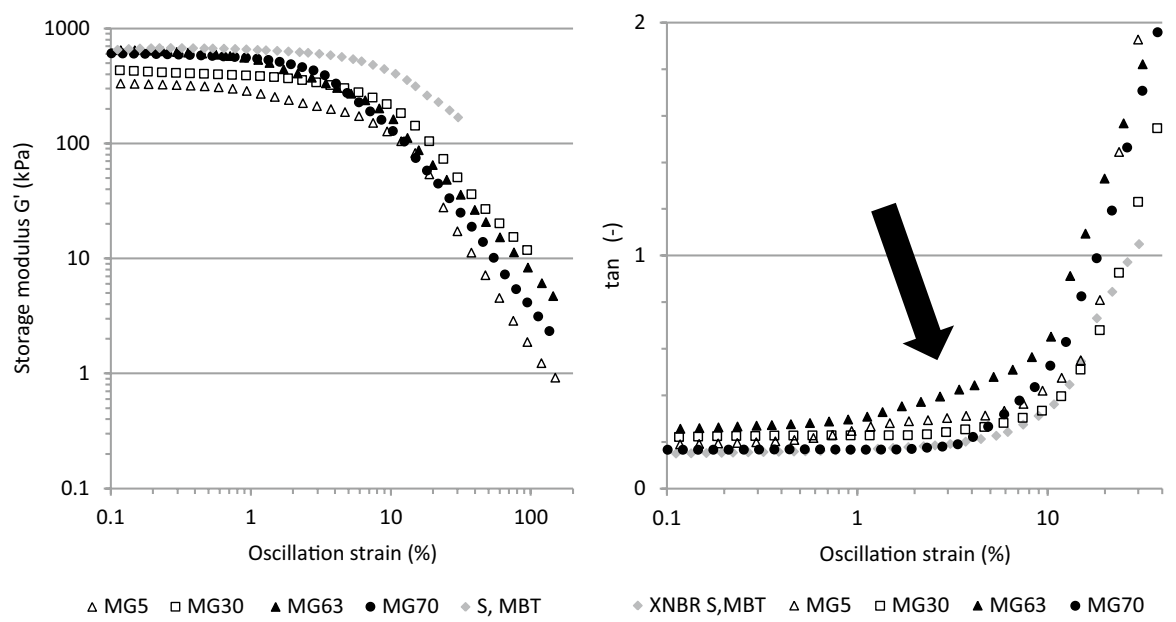

Fig. 7 The storage modulus $G^{\prime}(\mathrm{KPa})$ and loss factor $\tan \delta$ as a function of oscillation strain at $25^{\circ} \mathrm{C}$ for cured XNBR compounds (angular frequency $10 \mathrm{rad}^{\prime} \mathrm{s}^{-1}$ ) 
on LDHs surface can occur and this way also strengthen the reinforcing effect [26]. This type of interactions is usually destroyed up to $20 \%$ of oscillation strain [35].

The increase in mechanical loss $\tan \delta$ (Fig. 7) observed for MG63-XNBR above the $1 \%$ of oscillation strain confirmed that the movement of polymer chains was facilitated comparing to MG70-XNBR. This effect was a consequence of differences in formed ionic network. The lower amount of cross-links and the lability of ionic phase at lower temperature (lower value of $T_{\alpha^{\prime}}$ ) caused the changes in viscoelastic behavior and damping properties of material at $25{ }^{\circ} \mathrm{C}$ comparing with MG30 and MG70-XNBR (Fig. 7).

The frequency sweep tests were performed in the linear viscoelastic region at very low oscillation strain $(0.1 \%)$ and applying the higher oscillation strain (1\%) to estimate if the stretch influenced on the behavior of formed clusters. The dependencies of the shear storage modulus $G^{\prime}$ and shear loss modulus $G^{\prime \prime}$ at $25^{\circ} \mathrm{C}$ on angular frequency $\omega$ for MG-XNBR are shown in Fig. 8. For all the compositions at $25^{\circ} \mathrm{C}$, the storage moduli and loss moduli registered an increase with the frequency. At any given frequency, the aluminum-rich MG5 filler exhibited significant lower storage modulus $G^{\prime}$ than other MG fillers. The formation of more ordered ionic clusters had a meaningful impact on the behavior of MG-XNBR causing the reinforcement effect, as it was observed for MG30, MG63 and MG70 fillers. The incorporation of the magnesium rich MG63 and MG70 instead of MG30 increased the values of $G^{\prime}$ and $G^{\prime \prime}$ modulus in whole studied angular frequency range. Here, also, both compounds characterized more similar viscoelastic behavior as angular frequency was decreased. The formation of ionic phase, as confirmed by the presence of $T_{\alpha^{\prime}}$, led to the increase in storage modulus $G^{\prime}$ measured at high angular frequency $\omega$ (short time relaxation). The ordered ionic
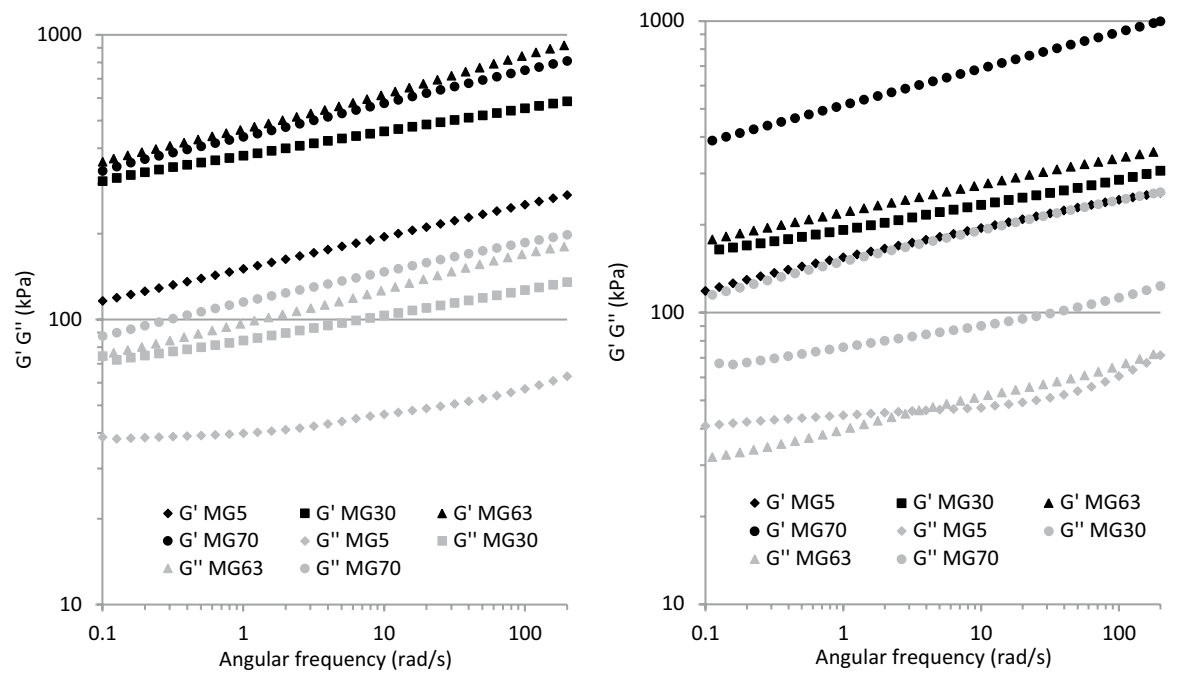

Fig. 8 The storage modulus $G^{\prime}(\mathrm{kPa})$ and loss shear modulus $G^{\prime \prime}$ as a function of an angular frequency at $25^{\circ} \mathrm{C}$ for cured XNBR compounds measured at linear viscoelastic region (oscillation strain $0.1 \%$ ) and at $1 \%$ of oscillation strain 
phase acted as reinforcing element at high angular frequency $\omega$. The mobility and ability to reorganization of formed ionic structure led to decrease in the storage modulus $G^{\prime}$ at low angular frequency and at long relaxation time.

The mechanical behavior of ionic phase depends on the structure of ionic aggregates [6]. Aggregates with a low number of ion pairs can undergo reorganization or even the destruction as a result of the slippage of loosely bonded polymer chains when the level of deformation increases. Under higher deformation, the changes in mechanical response can be observed. The changes of the values of storage modulus $G^{\prime}$ and loss modulus $G^{\prime \prime}$ measured at higher deformation (1\% of oscillation strain instead of $0.1 \%$ ) confirmed the differences in permanence and stability of formed ionic structure (Fig. 8). The significant decrease in storage shear modulus $G^{\prime}$ for MG30 and MG63-XNBR indicated that the application of such way cured XNBR should be limited to the low deformation conditions. According to frequency sweep studies, the higher deformation stability of MG70-XNBR predestines the Pural MG70 filler to be used for obtaining ionic elastomers.

The use of elastomers is not limited to the application at room temperature but also at subzero temperatures. The values of the shear storage modulus $G^{\prime}$ and shear loss modulus $G^{\prime \prime}$ at $-5{ }^{\circ} \mathrm{C}$ are shown in Fig. 9. At any given frequency, the higher values of storage shear modulus $G^{\prime}$ and loss shear modulus $G^{\prime \prime}$ were observed for the $\mathrm{Mg}-\mathrm{Al}-\mathrm{XNBR}$ rubber exhibited the ionic glass transition temperature $T_{\alpha^{\prime}}$. The increase in the storage modulus $G^{\prime}$ occurred in higher extent for magnesium rich MG63 and MG70 as compared with MG30-XNBR. The linear viscoelastic region at $-5{ }^{\circ} \mathrm{C}$ was extended for XNBR cured by magnesium rich MG63 and MG70 fillers comparing with MG30 and MG5-XNBR, as indicated by the changes of mechanical loss $\tan \delta$ as a function of oscillation strain (Supplementary Material, Fig. A14). Although the increase in $\tan \delta$ at room temperature
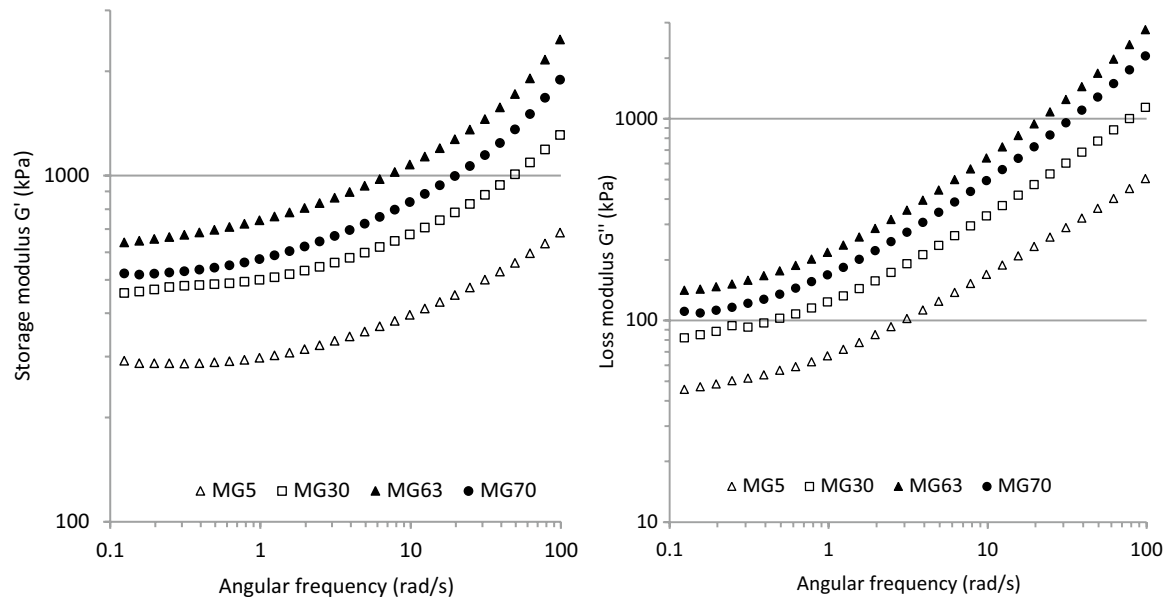

Fig. 9 The storage modulus $G^{\prime}(\mathrm{kPa})$ and loss modulus $G^{\prime \prime}$ as a function of frequency $\omega$ at $-5^{\circ} \mathrm{C}$ for cured XNBR compounds 
for MG63-XNBR started at about $1 \%$ of oscillation strain, it is worth underlined the better stability of damping properties observed for MG63-XNBR at $-5{ }^{\circ} \mathrm{C}$ temperature.

\section{The relaxation behavior}

Stress relaxation can be defined as the decrease in stress that occurs at applied constant strain. The relaxation of shear stresses is much faster than relaxation of normal stresses [44]. To illuminate the differences in mobility and behavior of formed ionic network in XNBR more clearly, the relaxation behavior of cured samples using fixed $0.05 \%$ shear stress was investigated. As reported in literature [45] stress relaxation occurs due to the physical relaxation caused by the relocation of the rubber chains and the fillers, when subjected to deformation. A reorientation of rubber network, the disengagement and re-engagement of chains entanglements, and the destruction of the secondary bonds between chain and filler particles result in decay of the stress required to maintain the fixed strain with time. Physical relaxation refers to the rearrangement and motion of polymer chains and the deformation or the rupture of ionic micro-domains and cross-links. Thus, it should be significantly influenced by the strength and the surrounding structure of the ionic clusters. Figure 10 illustrates plots between the relaxation stress and logarithm of time. The typical relaxation behavior was observed. Initially, fast stress decay slowed down with time as system approached equilibrium. The freedom of movement of rubber chains depended on the morphology of formed ionic network and the degree of cross-linking. The higher amount of energy stored in material and the higher values of initial stress $\sigma_{0}$ were observed for the magnesium rich MG-XNBR. The deformed chains trapped in ordered ionic phase cannot so easily retract. The relaxation plots of MG5-XNBR indicated lower values of initial stress $\sigma_{0}$. The stress relaxation plots
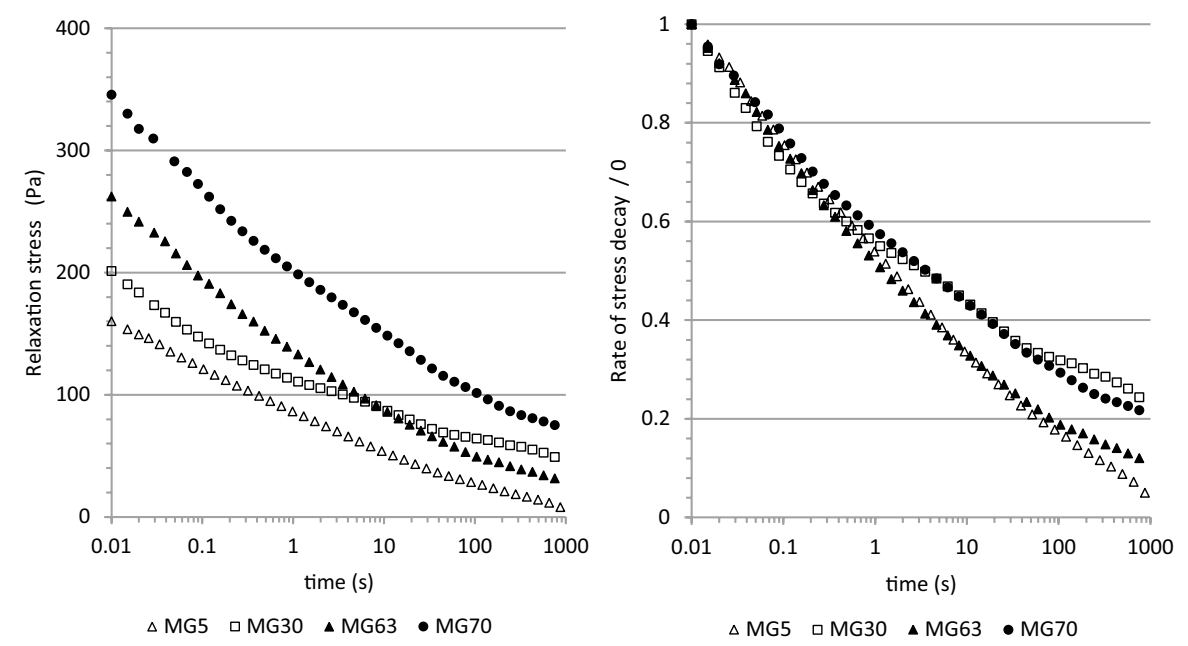

Fig. 10 The relaxation stress (applied shear strain $0.05 \%$ ) and rate of stress decay $\sigma / \sigma_{0}$ for XNBR 
for all MG-XNBR consisted of two or three straight lines of unequal slopes due to different mechanisms of relaxation. A fast stress relaxation was observed at short times for all rubbers. This relaxation was associated with the changes in orientation of small segments of molecular chains at the filler-matrix interface. The mechanism caused by a long-range rearrangement of formed ionic phase and/or the progressive failure of polymer-filler ionic bonding dominated at the later stage of relaxation. In order to compare the degree of relaxation, the relaxation curves were normalized with respect to initial stress $\sigma_{0}$. The normalized curves are presented in Fig. 10. Both MG30 and MG70-XNBR exhibited slower stress decay during the later stage of relaxation than MG63-XNBR. Moreover, the residual stress values obtained at the end of the relaxation measurements significantly varied for both rubber comparing to MG5-XNBR and MG63-XNBR. This could be explained on the basis of previous studies. The differences in the structure of formed ordered ionic phase and higher cross-link density of MG30 and MG70-XNBR vulcanizates caused different relaxation behavior. For both MG30 and MG70, the peaks of ionic transition were more visible. The higher amount of polymer chains was partly incorporated into the ordered ionic phase. The more restricted mobility of molecules entrapped in the ionic network caused a lower decrease in stress during the long-time relaxation. Hence, less pronounced long-term stress relaxation results were observed for MG30 and MG70-XNBR. The stronger stress decay for MG63-XNBR occurred due to the reactions over time indicating rupture of ionic cross-links and breaking of the bonds formed between filler particles and elastomer. The highest relaxation rate obtained for XNBR containing MG5 particles may be attributed to the much lower degree of cross-linking.

\section{Conclusions}

The rheological properties of XNBR cured by using different layered double hydroxides were analyzed. It was found that stronger tendency to create particles-particles interactions of aluminum-rich fillers MG5 and MG30 was responsible for an increase in the complex viscosity and calculated values of consistency index K. The stronger tendency to form the filler-filler structure was confirmed by higher values of oil absorption parameters OAPs (MG5 $140.1 \mathrm{~g}^{\prime} 100 \mathrm{~g}^{-1}$; MG30 $172.9 \mathrm{~g}^{\prime} 100 \mathrm{~g}^{-1}$ )

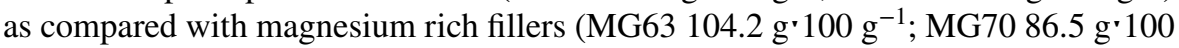
$\left.\mathrm{g}^{-1}\right)$. At the processing temperature of $80^{\circ} \mathrm{C}$, the uncured XNBR containing aluminum-rich filler MG5, MG30 exhibited higher values of the storage shear modulus. Effect was attributed to the larger surface area and interphase contact as well as the stronger tendency to create filler-filler interactions.

The DSC studies confirmed that some ionic pairs were formed during processing of magnesium rich MG63 and MG70-XNBR affected the glass transition temperature $T_{\mathrm{g}}$ of uncured rubber. The lower amount of $\mathrm{Mg}^{2+}$ in structure of MG30 filler shifted the range of curing temperatures $\left(136-223^{\circ} \mathrm{C}\right)$ as compared with magnesium rich MG70 $\left(88-187^{\circ} \mathrm{C}\right)$. The calculated values of the apparent energy of activation $E_{\mathrm{a}}$ confirmed that the amount of $\mathrm{Mg}^{2+}$ had the catalytic effect on XNBR curing. The agglomerated structure, the lower aspect ratio of MG63 particles restricted 
the accessibility to the active sites on the filler surface leading to lower values of rate constant $K$ of curing. As a result, the cross-link density of MG63-XNBR decreased comparing with MG70-XNBR.

The intensity of the relaxation transition of the soft segments at glass transition $T_{\mathrm{g}}$ was more pronounced for aluminum-rich filler MG5-XNBR. The MG30, MG63 and MG70-XNBR exhibited more restricted chains mobility. The relaxation transition of the ionic structure was detected for MG30, MG63 and MG70-XNBR. The ionic transition temperature $T_{\alpha^{\prime}}$ of MG63-XNBR was shifted to lower temperature $\left(32.95{ }^{\circ} \mathrm{C}\right)$ due to differences in formed ionic structure, as compared with MG30 and MG70-XNBR compounds. The increase in the loss tan $\delta$ observed for MG63-XNBR at room temperatures above the $1 \%$ of oscillation strain revealed that the movement of polymer chains was facilitated as a consequence of differences in formed ionic phase. Additionally, the lower permanence and stability of MG63-XNBR ionic phase were confirmed by more pronounced long-term stress relaxation. The stronger stress decay occurred due to facilitated rupture of ionic cross-links and the bonds between MG63 filler and elastomer.

Significant decrease in the storage modulus $G^{\prime}$ measured as a function of angular frequency at higher deformation ( $1 \%$ of oscillation strain instead of $0.1 \%$ ) was observed for MG30 and MG63-XNBR indicating that the application of such way cured rubber should be limited to low-strain conditions.

Due to analysis of the viscoelastic properties, especially higher deformation stability, the Pural MG70 HT is recommended for obtaining ionic XNBR elastomers.

Open Access This article is licensed under a Creative Commons Attribution 4.0 International License, which permits use, sharing, adaptation, distribution and reproduction in any medium or format, as long as you give appropriate credit to the original author(s) and the source, provide a link to the Creative Commons licence, and indicate if changes were made. The images or other third party material in this article are included in the article's Creative Commons licence, unless indicated otherwise in a credit line to the material. If material is not included in the article's Creative Commons licence and your intended use is not permitted by statutory regulation or exceeds the permitted use, you will need to obtain permission directly from the copyright holder. To view a copy of this licence, visit http://creativecommons.org/licen ses/by/4.0/.

\section{References}

1. Seghar S, Asaro L, Rolland-Monnet M, Hocine A (2019) Thermo-mechanical devulcanization and recycling of rubber industry waste. Res Cons Rec 144:180-186. https://doi.org/10.1016/j.resco nrec.2019.01.047

2. Wang D, Zhang H, Cheng B, Qian Z, Liu W, Zhao N, Xu J (2016) Dynamic cross-links to facilitate recyclable polybutadiene elastomer with excellent toughness and stretchability. J Polym Sci Part A: Polym Chem 54:1357-1366. https://doi.org/10.1002/pola.27983

3. Peng Y, Yang Y, Wu Q, Wang S, Huang G, Wu J (2018) Strong and tough self-healing elastomer enabled by dual reversible networks formed by ionic interactions and dynamic covalent bonds. Polymer 157:172-179. https://doi.org/10.1016/j.polymer.2018.09.038

4. Jia Z, Zhu S, Chen Y, Zhang W, Zhong B, Jia D (2020) Recyclable and self-healing rubber composites based on thermoreversible dynamic covalent bonding. Compos A 129:105709. https://doi. org/10.1016/j.compositesa.2019.105709 
5. Mukhopadhyay S, Sahu P, Bhajiwala H, Mohanty S, Gupta V, Bhowmick AK (2019) Synthesis, characterization and properties of self-healable ionomeric carboxylated styrene-butadiene polymer. J Mater Sci 54:14986-14999. https://doi.org/10.1007/s10853-019-03921-X

6. Basu D, Das A, Stöckelhuber KW, Jehnichen D, Formanek P, Sarlin E, Vuorinen J, Heinrich G (2014) Evidence for an in situ developed polymer phase in ionic elastomers. Macromol 47:34363450. https://doi.org/10.1021/ma500240v

7. Fleischmann DD, Ayalur-Karunakaran S, Arbeiter F, Schaller R, Holzner A, Kern W, Schlögl S (2018) Influence of crosslinker and water on mechanical properties of carboxylated nitrile butadiene rubber (XNBR). Polym Testing 66:24-31. https://doi.org/10.1016/j.polymertesting.2018.01.001

8. Przybyszewska M, Zaborski M (2009) The effect of zinc oxide nanoparticle morphology on activity in crosslinking of carboxylated nitrile elastomer. EXPRESS Polym Lett 3(9):542-552. https://doi. org/10.3144/expresspolymlett.2009.68

9. Krzemińska SM, Smejda-Krzewicka AA, Leniart A, Lipińska L, Woluntarski M (2020) Effects of curing agents and modified graphene oxide on the properties of XNBR composites. Polym Testing 83:106368. https://doi.org/10.1016/j.polymertesting.2020.106368

10. Ibarra L, Marcos-Fernández A, Alzorriz M (2002) Mechanistic approach to the curing of carboxylated nitrile rubber (XNBR) by zinc peroxide/zinc oxide. Polymer 43:1649-1655. https://doi. org/10.1016/S0032-3861(01)00734-0

11. Ibarra L, Alzorriz M (2002) Ionic elastomers based on carboxylated nitrile rubber (XNBR) and zinc peroxide: influence of carboxylic group content on properties. J Appl Polym Sci 84:605-615. https ://doi.org/10.1002/app.10313

12. Ibarra L, Alzorriz M (2003) Ionic elastomers based on carboxylated nitrile rubber and calcium oxide. J Appl Polym Sci 87:805-813. https://doi.org/10.1002/app.11468

13. Ibarra L, Alzorriz M (2007) Ionic elastomers based on carboxylated nitrile rubber and magnesium oxide. J Appl Polym Sci 103:1894-1899. https://doi.org/10.1002/app.25411

14. Lipińska M (2017) Nitrile Elastomer/LDH composites with varying Mg/Al ratio, curing, nanoparticles dispersion and mechanical properties. In: Çankaya N (ed) Elastomers. Intech, Zagreb, pp 39-74. https://doi.org/10.5772/intechopen.68384

15. Bhawal P, Das TK, Ganguly S, Mondal S, Das NCh (2019) Selective cross-linking of carboxylated acrylonitrile butadiene rubber and study of their technological compatibility with poly(ethylene-comethyl acrylate) by means of mechanical, thermal, and chemical analysis. Polym Bull 76:18771897. https://doi.org/10.1007/s00289-018-2474-z

16. Basu D, Das A, Stöckelhuber KW, Wagenknecht U, Heinrich G (2014) Advances in layered double hydroxide (LDH)-based elastomer composites. Prog Polym Sci 39:594-626. https://doi. org/10.1016/j.progpolymsci.2013.07.011

17. Wang Y, Wang F, Gao S, Lu Y, Liu J, Zhu H (2019) Two-dimensional layered double hydroxides nanoplatelets assembled in situ on $\mathrm{SiO}_{2}$ nanoparticles for high-performing hydrogenated nitrile butadiene rubber. Comp Sci Tech 182:107742. https://doi.org/10.1016/j.compscitech.2019.107742

18. Arrigo R, Tzankova DN, Tarantino G, Passaglia E, Coiai S, Cicogna F, Filippi S, Nasillo G, Chillura MD (2018) An insight into the interaction between functionalized thermoplastic elastomer and layered double hydroxides through rheological investigations. Compos B 139:47-54. https://doi. org/10.1016/j.compositesb.2017.11.060

19. Wu T, Lai X, Li H, Chen Y, Wang Y, Liu T, Zeng X (2020) Synergistic enhancement of vinyltriethoxysilane and layered $\mathrm{Mg}-\mathrm{Al}$ double hydroxide on the tracking and erosion resistance of silicone rubber. Polym Testing 84:106373. https://doi.org/10.1016/j.polymertesting.2020.106373

20. Qiu J, Lai X, Li H, Gao J, Zeng X, Liao X (2019) Facile fabrication of a novel polyborosiloxanedecorated layered double hydroxide for remarkably reducing fire hazard of silicone rubber. Compos B 175:107068. https://doi.org/10.1016/j.compositesb.2019.107068

21. He X, Li T, Shi Z, Wang X, Xue F, Wu Z (2016) Thermal-oxidative aging behavior of nitrile-butadiene rubber/ functional LDHs composites. Polym Deg Stab 133:219-226. https://doi.org/10.1016/j. polymdegradstab.2016.08.018

22. Mishra G, Dash B, Pandey S (2018) Layered double hydroxides: A brief review from fundamentals to application as evolving biomaterials. App Clay Sci 153:172-186. https://doi.org/10.1016/j. clay.2017.12.021

23. Ezeh CI, Tomatis M, Yang X, He J, Sun Ch (2018) Ultrasonic and hydrothermal mediated synthesis routes for functionalized $\mathrm{Mg}-\mathrm{Al} \mathrm{LDH}$ : comparison study on surface morphology, basic site strength, cyclic sorption efficiency and effectiveness. Ultrason Sonochem 40:341-352. https://doi. org/10.1016/j.ultsonch.2017.07.013 
24. Zümreoglu-Karan B, Ay H (2012) Layered double hydroxides-multifunctional nanomaterials. Chem Pap 66(1):1-10. https://doi.org/10.2478/s11696-011-0100-8

25. Mills SJ, Christy AG, Genin JMR, Kameda T, Colombo F (2012) Nomenclature of the hydrotalcite supergroup: natural layered double hydroxides. Mineral Mag 76(5):1289-1336

26. Pradhan S, Costa FR, Wagenknecht U, Jehnichen D, Bhowmick AK, Heinrich G (2008) Elastomer/ LDH nanocomposites: synthesis and studies on nanoparticle dispersion, mechanical properties and interfacial adhesion. Eur Polym J 44:3122-3132. https://doi.org/10.1016/j.eurpolymj.2008.07.025

27. Costa FR, Pradhan S, Wagenknecht U, Bhowmick AK, Heinrich G (2010) XNBR/LDH nanocomposites: effect of vulcanization and organic modifier on nanofillers dispersion and strain-induced crystallization. J Polym Sci Part B: Polym Phys 48:2302-2311. https://doi.org/10.1002/polb.22116

28. Laskowska A, Zaborski M, Boiteux G, Gain O, Marzec A, Maniukiewicz W (2014) Ionic elastomers based on carboxylated nitrile rubber (XNBR) and magnesium aluminium layered double hydroxide (hydrotalcite). EXPRESS Polym. Lett. 8(6):374-386. https://doi.org/10.3144/expresspol ymlett.2014.42

29. Arrigo R, Dintcheva NT, Tarantino G, Passaglia E, Coiai S, Cicogna F, Filippi S, Nasillo G, Martino DCh (2018) An insight into the interaction between functionalized thermoplastic elastomer and layered double hydroxides through rheological investigations. Compos B 139:47-54. https://doi. org/10.1016/j.compositesb.2017.11.060

30. Laskowska A, Zaborski M, Boiteux G, Gain O, Marzec A (2014) Effect of unmodified layered double hydroxides MgAl-LDHs with various structures on the properties of filled carboxylated acrylonitrile-butadiene rubber XNBR. Eur Polym J 60:172-185. https://doi.org/10.1016/j.eurpo lymj.2014.09.013

31. Wagner M (2009) Thermal analysis in practice. Collected applications. Mettler Toledo, Schwarcenbach

32. Isayev AI, Deng JS (1988) Nonisothermal vulcanization of rubber compounds. Rubber Chem Tech 61:340-361

33. Flory PJ, Rehner J (1943) Statistical mechanics of cross-linked polymer networks. II Swelling J Chem Phys 11:521-526. https://doi.org/10.1063/1.1723792

34. Dick JS (2009) Compound processing characteristics and testing. Rubber technology compounding and testing for performance. Hanser Publishers, Münich, pp 17-45

35. Lipińska M, Soszka K (2019) Viscoelastic behavior, curing and reinforcement mechanism of various silica and POSS filled methyl-vinyl polysiloxane MVQ rubber. Silicon 11:2293-2305. https:// doi.org/10.1007/s12633-019-0081-8

36. Pagès P, Lacorte T, Lipińska M, Carrasco F (2008) Study of curing of layered silicate/trifunctional epoxy nanocomposites by means of FTIR spectroscopy. J Appl Polym Sci 108(4):2107-2115. https ://doi.org/10.1002/app.27853

37. Maciejewska M, Zaborski M (2017) Thermal analysis and mechanical methods applied to studying properties of SBR compounds containing ionic liquids. Polym Testing 61:349-363. https://doi. org/10.1016/j.polymertesting.2017.05.041

38. Lipińska M, Imiela M (2019) Morphology, rheology and curing of (ethylene-propylene elastomer/ hydrogenate acrylonitrile-butadiene rubber) blends reinforced by POSS and organoclay. Polym Testing 75:26-37. https://doi.org/10.1016/j.polymertesting.2019.01.020

39. Vidal A, Haidar B (2007) Filled elastomers: characteristics and properties of interfaces and their role in reinforcement processes. Soft Mater 5:155-167. https://doi.org/10.1080/153944507015546 50

40. Bagshaw CR (2013) Order of reaction. In: Roberts GCK (ed) Encyclopedia of biophysics. Springer, Berlin

41. Zaborski M, Owczarek M, Paryjczak T, Kazimierczak A (2002) Właściwości karboksylowanego kauczuku butadienowo-akrylonitrylowego usieciowanego za pomocą układu $\mathrm{ZnO} / \mathrm{SiO}_{2}$. Polimery 47:339-346

42. Gaca M, Pietrasik J, Zaborski M, Okrasa L, Boiteux G, Gain O (2019) Effect of zinc oxide modified silica particles on the molecular dynamics of carboxylated acrylonitrile-butadiene rubber composites. Polymers 9:645. https://doi.org/10.3390/polym9120645

43. Payne AR (1962) The dynamic properties of carbon black-loaded natural rubber vulcanizates. Part 1. J Appl Polym Sci 6:57-63. https://doi.org/10.1002/app.1962.070061906

44. Malkin AY, Avraam I, Isayev AI (2012) Viscoelasticity. In: Malkin AY, Avraam I, Isayev AI (eds) Rheology concepts, methods and applications, 2nd edn. ChemTec Publishing, Toronto, pp 43-126. https://doi.org/10.1016/B978-1-895198-49-2.50007-4 
45. Abu-Abdeen M (2010) Single and double-step relaxation and constitutive modeling of viscoelastic behavior of swelled and un-swelled natural rubber loaded with carbon black. Mater Des 31:20782084. https://doi.org/10.1016/j.matdes.2009.10.006

Publisher's Note Springer Nature remains neutral with regard to jurisdictional claims in published maps and institutional affiliations. 